\title{
Green tea powder and Lactobacillus plantarum affect gut microbiota, lipid metabolism and inflammation in high-fat fed C57BL/6J mice
}

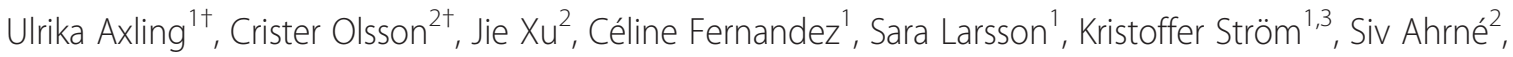
Cecilia Holm¹, Göran Molin ${ }^{2+}$ and Karin Berger ${ }^{1 *+}$

\begin{abstract}
Background: Type 2 diabetes is associated with obesity, ectopic lipid accumulation and low-grade inflammation. A dysfunctional gut microbiota has been suggested to participate in the pathogenesis of the disease. Green tea is rich in polyphenols and has previously been shown to exert beneficial metabolic effects. Lactobacillus plantarum has the ability to metabolize phenolic acids. The health promoting effect of whole green tea powder as a prebiotic compound has not been thoroughly investigated previously.

Methods: C57BL/6J mice were fed a high-fat diet with or without a supplement of 4\% green tea powder (GT), and offered drinking water supplemented with Lactobacillus plantarum DSM 15313 (Lp) or the combination of both $(L p+G T)$ for 22 weeks. Parameters related to obesity, glucose tolerance, lipid metabolism, hepatic steatosis and inflammation were examined. Small intestinal tissue and caecal content were collected for bacterial analysis.

Results: Mice in the Lp + GT group had significantly more Lactobacillus and higher diversity of bacteria in the intestine compared to both mice in the control and the GT group. Green tea strongly reduced the body fat content and hepatic triacylglycerol and cholesterol accumulation. The reduction was negatively correlated to the amount of Akkermansia and/or the total amount of bacteria in the small intestine. Markers of inflammation were reduced in the LP + GT group compared to control. PLS analysis of correlations between the microbiota and the metabolic variables of the individual mice showed that relatively few components of the microbiota had high impact on the correlation model.
\end{abstract}

Conclusions: Green tea powder in combination with a single strain of Lactobacillus plantarum was able to promote growth of Lactobacillus in the intestine and to attenuate high fat diet-induced inflammation. In addition, a component of the microbiota, Akkermansia, correlated negatively with several metabolic parameters known to be risk factors for the development of type 2 diabetes.

Keywords: Green tea, Lactobacillus plantarum, Type 2 diabetes, Obesity, Microbiota, Akkermansia, Inflammation, C57BL/6J

\footnotetext{
* Correspondence: karin.berger@med.lu.se

${ }^{\dagger}$ Equal contributors

${ }^{1}$ Department of Experimental Medical Science, Lund University, Lund,

Sweden

Full list of author information is available at the end of the article
} 


\section{Background}

The prevalence of obesity and associated type 2 diabetes is increasing rapidly and is a worldwide health problem [1]. The mechanisms whereby obesity leads to insulin resistance and type 2 diabetes involve ectopic lipid accumulation and low-grade inflammation. Non-alcoholic fatty liver disease is strongly associated with both obesity and type 2 diabetes [2]. Also, the pathogenesis of obesity and type 2 diabetes has been associated with a dysfunctional gut microbiota $[3,4]$. The mammalian gut is colonised with a diverse range of microorganisms that are known to play an important role in host metabolism $[3,5,6]$. Manipulation of the microbiota in mice using prebiotics [7] or antibiotics [8,9] has been shown to have beneficial effects on adiposity, glucose tolerance and inflammation. Also, addition of a probiotic mixture of strains has been shown to improve high-fat diet-induced hepatic steatosis, inflammation and insulin sensitivity in rodents $[10,11]$. Thus, the composition of the gut microbiota seems to play an important role in the regulation of lipid and glucose metabolism, as well as in inflammatory pathways.

Most studies on the microbiota in animals and humans have focused on caecum (rodents), colon (humans) or faeces as a reflection of the caecal or colonic microbiota. However, the small intestine appears to play an important role in the development of obesity and type 2 diabetes, as illustrated by the outcome of bariatric surgery where by-passing parts of the upper human gastrointestinal tract promotes weight-loss, ameliorate type 2 diabetes and improves hyperlipidemia [12].

Green tea is suggested to possess health promoting properties. It is a rich source of polyphenols, especially catechins, which represent approximately 30\% of fresh leaf dry weight [13]. Extract from green tea or tea catechins have previously been shown to have anti-obesity and anti-diabetic effects in animal models [14-19] as well as in humans [20-22]. Most studies regarding health effects of green tea have been performed on tea extract or catechin fractions. Few studies have dealt with the effects of powdered whole green tea leafs, which include both water- and non-water soluble polyphenols as well as dietary fibres. Green tea powder is increasingly included as a supplementary ingredient in foods, e.g. in bakeries and desserts. Green tea catechins are poorly absorbed in the intestine and are thus present in the intestinal lumen where they are suggested to inhibit lipid absorption by forming complexes with lipids and lipolytic enzymes [23].

The species Lactobacillus plantarum (L. plantarum) has the ability to metabolize phenolic acids [24] and to split up tannins $[25,26]$. The metabolites are presumably more easily absorbed and distributed into the tissues where they can act as antioxidants and electron scavengers. Phenolic compounds can also have antimicrobial effects that may affect the composition of the gut microbiota, in favour of polyphenol-metabolizing components of the microbiota [27]. Also, green tea extracts have been shown to selectively inhibit the growth of pathogenic bacteria while either enhancing or not affecting the growth of beneficial bacteria like lactic acid bacteria [28-30]. To the best of our knowledge, the impact of green tea powder as a prebiotic compound to promote lactobacilli or other health promoting components of the microbiota has not previously been evaluated.

We report here a comprehensive study on the effects of green tea powder, with or without the addition of $L$. plantarum DSM 15313, on metabolic parameters and on the microbiota in both the small intestine and in the caecum of high-fat fed C57BL/6J mice. Our results demonstrate that the combination of green tea powder and L. plantarum alter the intestinal microbiota, reduce inflammation and affect cholesterol metabolism in a mouse model for human obesity and insulin resistance.

\section{Methods}

\section{Animals and study design}

The study followed the European Community regulations for animal experiments and was approved by the local animal ethics committee, Lund, Sweden, (permission number M202-08). Eight-week old female C57BL/ 6JBomTac mice, weighing 18.2 $\pm 2.2 \mathrm{~g}$ (Taconic, Skensved, Denmark) were housed 7 mice/cage in a controlled environment (12 hour light cycle). After one week of acclimatization, the mice were randomly divided into four groups $(n=21)$, and thereafter fed the experimental diets ad libitum with free access to drinking water. The two experimental diets were high-fat diets (HFD, 45 energy\% fat; Research Diets, NB, USA), with (D08021404) or without (D12451N) supplement of $4 \%$ (w/w) powdered green tea leaves (Camellia sinensis, Premium Powdered Sencha, www.JapaneseGreenTeaOnline. com). The green tea powder was analyzed for nutritional content including water soluble and insoluble fibers (Eurofins, Lidköping, Sweden) as well as water soluble and insoluble polyphenols, see Additional files 1 and 2, respectively. The drinking water was supplemented with $1.5 \%(\mathrm{v} / \mathrm{v})$ of either freezing medium $\left(3.6 \mathrm{mM} \mathrm{K} \mathrm{HPO}_{4}\right.$, $1.3 \mathrm{mM} \mathrm{KH} \mathrm{KH}_{4}, 2.0 \mathrm{mM}$ sodium citrate, $1.0 \mathrm{mM}$ $\mathrm{MgSO}_{4}, 12 \%$ glycerol) or L. plantarum DSM 15313 (strain HEAL19, Probi AB, Lund, Sweden) suspended in freezing medium to a concentration of $3 \times 10^{9} \mathrm{cfu} / \mathrm{ml}$ drinking water, giving an approximate intake of $1 \times$ $10^{10} \mathrm{cfu} /$ day. The concentrated aliquots of bacteria suspension were stored in $-20^{\circ} \mathrm{C}$ and mixed with fresh tap water on a daily basis. L. plantarum has previously been shown to be stable during 24 hours in tap water at room 
temperature [31]. Food intake (on a per cage basis) and body weights were registered once a week. After 5, 11 and 22 weeks, body fat mass was analyzed using dualenergy X-ray absorptiometry technique with a Lunar PIXImus densitometer (GE Medical Systems). Oral glucose tolerance tests were performed after 8 and 21 weeks and an intravenous insulin tolerance test was performed after 15 weeks. Two mice in the Lp group did not wake up from the anaesthesia after the first oral glucose tolerance test. Faeces were collected at three different time points during the study. Mice were placed in clean cages with a minimum of bedding for 24 hours. Faeces from each cage was collected, lyophilized and grounded in a mortar and stored at $-20^{\circ} \mathrm{C}$ until analysis. After 11 weeks, 10 mice in each group were sacrificed in order to study time dependency of the treatment, and after 22 weeks, the remaining mice (9-11 per group) were sacrificed. At the time of sacrifice, mice were fasted for 4 hours and thereafter anesthetized with an intraperitoneal injection of midazolam (Dormicum, Hoffman- La Roche, Basel, Switzerland) and a mixture of fluanison/ fentanyl (Hypnorm, Janssen, Beerse, Belgium). Blood was drawn by intraorbital puncture followed by cervical dislocation. Periovarian white adipose tissue, liver (rinsed with PBS) and spleen were weighed and snap-frozen in liquid nitrogen. A part of the duodenum (3-10 mm distally of pylorus) was collected in buffer containing $10 \mathrm{mM}$ Tris- $\mathrm{HCl}$ and $1 \mathrm{mM}$ EDTA, $\mathrm{pH}$ 8.0, and snapfrozen in liquid nitrogen. The caecum including its content was weighed and thereafter the wall was removed. Parts of the content were frozen in freezing medium for culture of bacteria and parts were snap frozen for extraction of bacterial DNA. All samples were stored at $-80^{\circ} \mathrm{C}$ until analysis.

\section{Viable count}

Plate count was performed on the caecum content and the samples were cultivated on Violet Red Bile Dextrose agar (Enterobacteriaceae) incubated aerobically at $37^{\circ} \mathrm{C}$ for 24 hours and on Rogosa agar (lactobacilli) incubated anaerobically at $37^{\circ} \mathrm{C}$ for 48 hours. From Rogosa plates, 1-2 colonies morphologically resembling L. plantarum were picked for tentative identification of $L$. plantarum DSM 15313 by Random Amplified Polymorphic DNA (RAPD) analysis (for details regarding RAPD see Additional file 3).

\section{DNA extraction from intestinal samples}

DNA was extracted from the caecum content using a Biorobot EZ1 and a DNA Tissue Kit (Qiagen AB, Sollentuna, Sweden) as previously described [32]. Extracted DNA was eluted in $200 \mu \mathrm{l}$ by the Biorobot EZ1 according to the manufacturer's instruction.

\section{Amplification and T-RFLP analysis}

The universal primers ENV1 and ENV2 were used for amplification of the bacterial 16S rRNA genes [33]. The forward ENV1 primer was fluorescently labelled with FAM. The amplicons were then purified and digested with the restriction endonuclease MspI. For caecum samples the restriction endonuclease AluI (Fermenta Life Science) was also used (for details see Additional file 3). Samples were analyzed at DNA-lab (SUS, Malmö, Sweden). The total area was summarized for each sample and the relative area for each T-RF was calculated and expressed as a percentage of the total area. In order to identify peaks in the T-RFLP profile a pure culture of L. plantarum DSM 15313 and a selected clone obtained previously from mouse caecum content that had been identified by partial sequencing of the $16 \mathrm{~S}$ rRNA genes as Akkermansia (unpublished results) were digested by MspI and analyzed by T-RFLP.

\section{Cloning and sequencing of the 16S rRNA genes}

The bacterial 16S rRNA genes of the small intestinal samples were amplified with the primers ENV1 and ENV2. The cloning was performed using the pGEM-T vector system II (Promega, Madison, USA) as previously described [33]. Randomly selected clones were harvested and stored in freezing media at $-80^{\circ} \mathrm{C}$ (for details regarding cloning see Additional file 3 ). Clones were sent to MWG-Biotech (MWG-Biotech, Ebersberg, Germany) for sequencing using the primer Univ0519-a-A-18 GWA TTA CCG CGG CKG CTG [34]. Approximately the first 450 bases were sequenced and the obtained sequences of $16 \mathrm{~S}$ rRNA genes were checked and edited manually using Bioedit Sequence Alignment Editor Version 7.0.9.0 [35]. The sequences were compared with the Ribosomal Database Project, release 10 using the option "Sequence Match" (Ribosomal Database Project, http://rdp.cme.msu.edu/) [36]. Clone sequences were also compared by using the option "similarity table", found at http://mobyle.pasteur. fr/cgi-bin/portal.py\#forms::dnadist. Ten clones were selected, one from each operational taxonomic unit containing sequences showing $>98 \%$ similarity, and submitted to GenBank. The accession numbers are JX971027-JX971036. Sequences are named with the acronym Msi (mice small intestine).

SYBR Green quantitative PCR of bacteria in small intestine Quantitative PCR (qPCR) was run separately in a Mastercycler $^{\circledR}$ ep realplex 1.5 real-time PCR system (Eppendorf) using primers for Lactobacillus, Akkermansia, Enterobacteriaceae and total bacteria (for primer sequences and details see Additional files 3 and 4). The standards for qPCR were prepared by cloning the target fragments of the $16 \mathrm{~S}$ rRNA genes from $L$. plantarum 
CCUG 35035 and E. coli CCUG 29300 (Culture collection, University of Gothenburg, Sweden). The former was used as template for Lactobacillus and total bacteria and the latter for Enterobacteriaceae. For Akkermansia a previously obtained clone from mouse caecum was used for the preparation of a standard (for details see Additional file 3).

\section{Diversity index}

For comparison of the microbial diversity between the groups both the Shannon and Simpson's diversity indices were calculated $[37,38]$. Both indices take evenness and species richness into account but the Simpson index is more weighted towards the abundance of the most common species than species richness [38]. The area of each $\mathrm{T}-\mathrm{RF}$, expressed as the proportion of the total area for a sample, was used for calculation.

\section{Lipid extraction from faeces and liver}

Lipids in faeces were extracted with hexane:isopropanol (3:2) and dried under nitrogen. The lipids were redissolved in isopropanol. Whole liver was grounded to a homogenous powder in a mortar in liquid nitrogen. An aliquot of the powdered liver was homogenized in phosphate buffered saline and thereafter lipids were extracted with chloroform:methanol (2:1) overnight. The organic phase was washed, dried under nitrogen and resuspended in chloroform. Triacylglycerol (TAG) and cholesterol were analyzed (Infinity, Thermo Electron Melbourne, Australia).

\section{RNA preparation from liver tissue and real-time qPCR}

Total RNA was isolated from grounded liver (see above) using the RNeasy Mini Plus Kit (Qiagen, Hilden, Germany) according to the manufacturer's instruction. Total RNA $(1 \mu \mathrm{g})$ was treated with DNaseI amplification grade (Invitrogen, Carlsbad, CA, USA) and reversely transcribed using random hexamers (Amersham Bioscieces, Piscataway, NJ, USA) and SuperScript II RNaseH reverse transcriptase (Invitrogen) according to the manufacturer's recommendations. The cDNA was used for quantitative PCR using TaqMan chemistry (assays-on-demand, Applied Biosystems) or SYBR green chemistry (primers were designed using the software Primer Express, Applied Biosystems), with an ABI 7900 system (Applied Biosystem, Foster City, CA, USA), see Additional file 5 for assay IDs of the Taqman probes and list of primer sequences. The relative quantification of mRNA was calculated using the $\Delta \Delta \mathrm{Ct}$-method with normalization by geometric average of the two housekeeping genes ribosomal protein S29 (RPS29) and glyceraldehyde-3-phosphate dehydrogenase (GAPDH) [39].

\section{Oral glucose tolerance test}

Mice fasted for 10 hours ( 9 p.m. -7 a.m.) were anesthetized with 0.4-0.6 mg Fluanison, 0.01-0.02 mg Fentanyl (Hypnorm) and 0.2-0.3 mg Midazolam (Dormicum) per mouse. D-glucose $(75 \mathrm{mg}$ in $0.5 \mathrm{ml})$ was given by intragastric gavage. Blood samples were drawn by intraorbital puncture using an EDTA-coated glass pipette at 0, 15, 30, 60 and $120 \mathrm{~min}$ after glucose administration. After immediate centrifugation plasma was collected and stored at $-20^{\circ} \mathrm{C}$ until analysis of glucose and insulin.

\section{Insulin tolerance test}

Mice fasted for 4 hours ( 9 a.m.-1 p.m.) were anesthetized as above. Insulin (Actrapid ${ }^{\circledR}$, Novo Nordisk A/S, Denmark) was injected intraperitoneally $(0.75 \mathrm{mU} / \mathrm{g}$ body weight). Blood samples were drawn as above at 0 , $15,30,45,60$ and 90 minutes after insulin administration for glucose analysis.

\section{HOMA index}

Insulin resistance was assessed by the homeostasis model assessment (HOMA), a mathematical model describing the degree of insulin resistance from fasting glycaemia and insulineamia. HOMA-IR is calculated by multiplying fasting plasma insulin $(\mathrm{mU} / \mathrm{l})$ with fasting plasma glucose (mmol/l) divided by 22.5 [40].

\section{Plasma samples}

At week 11 and 22 blood was drawn from 4 hour fasted anesthetized mice by intraorbital puncture. Plasma was prepared and stored as above. Glucose, cholesterol, TAG (Infinity, Thermo Electron Melbourne, Australia), nonesterified fatty acids (NEFA) (NEFA C, Wako Chemicals, Neuss, Germany), fructosamine (VetSpec ${ }^{\mathrm{TM}}$, Catachem Inc., Oxford, CT, USA) and alanine aminotransferase (ALT) (DiscretePak ${ }^{\mathrm{TM}}$, Catachem Inc.) were measured enzymatically. Insulin and adiponectin were measured radioimmunochemically (Linco Research, St Charles, MO, USA). Leptin, interleukin-6 (IL-6), monocyte chemoattractant protein -1 (MCP-1) and plasminogen activator inhibitor-1 (PAI-1) were analyzed in an aliquot of plasma that had been snap-frozen in liquid nitrogen and stored at $-80^{\circ} \mathrm{C}$ using Luminex technology (LX200, Luminex Corporation, Austin, TX, USA). Before the onset of the study 10 mice were sacrificed and blood was collected to measure baseline glucose and insulin.

\section{Statistics}

For the bacterial analyses, multiple groups' comparisons were performed using Kruskal-Wallis test, pair-wise comparisons using Nemenyi-Damico-Wolfe-Dunn test (NDWD), and correlations using Spearman's rank correlation test with Bonferroni correction for multiple testing. Correlation tests were carried out between the total 
amount of bacteria in the small intestine, amount of Lactobacillus and Akkermansia as well as small intestinal and caecal diversity, and body weight, total body fat content, periovarian white adipose tissue, plasma leptin, plasma fructosamine, basal plasma glucose and insulin, the area under the curve for the oral glucose tolerance tests, liver weight, hepatic TAG content, plasma ALT, plasma TAG, plasma NEFA, plasma adiponectin, plasma PAI-1, spleen weight and caecum weight. The statistical tests were performed using the stat package $[41,42]$ and the add-on package "coin" $[43,44]$ in the statistical software $\mathrm{R}$ (version 2.10.1, R Development Core Team, 2009).

For the rest of the data, one-way analysis of variance (ANOVA) with Bonferroni's multiple comparison post-test was used when the data was Gaussian distributed according to D'Agostino and Pearson omnibus normality test. When not normally distributed, Kruskal-Wallis non-parametric test with Dunn's multiple comparison post-test was used. Also, two-way ANOVA with Bonferroni post-test was used to compare body weights. The statistical analyses were performed with the GraphPad Software (GraphPad Prism 5.0, San Diego, CA, USA). All tests were two-sided and data were considered significant if $P<0.05$.

\section{Multivariate data analysis}

Principal component analysis (PCA) was applied to the T-RFLP data (a matrix of the relative peak area) and to the metabolic data in order to clarify cluster-structures in the data sets (SIMCA-P software, version 12.0.1; Umetrics, Umeå, Sweden). The two sets of data were used to build a Partial Least Squares Projections to Latent Structures (PLS) model in order to find correlations between them (Autofit in the SIMCA-P). First, all the metabolic parameters were used to build the PLS model, thereafter, those with $\mathrm{Q} 2<0.2$, which indicates a weak correlation against the small intestinal or caecal T-RFLP pattern, were excluded from the model.

\section{Results}

\section{Microbiota of the small intestine}

The microbiota of the small intestine was analyzed by qPCR and T-RFLP at 22 weeks. Two samples were also subjected to cloning and sequencing of the $16 \mathrm{~S}$ rRNA genes. The PCR-quantified load of Lactobacillus differed between the groups after 22 weeks $(p=0.002)$. Pair wise comparison showed that the Lp + GT group had significantly more Lactobacillus than the control group ( $\mathrm{p}=$ 0.002 ) and the GT group ( $\mathrm{p}=0.04$ ) (Figure 1). No differences in the amount of the Gram-negative and mucin degrading genus Akkermansia (belonging to the phylum Verrucomicrobia) or total amount of bacteria were observed between the groups. The mean values of log

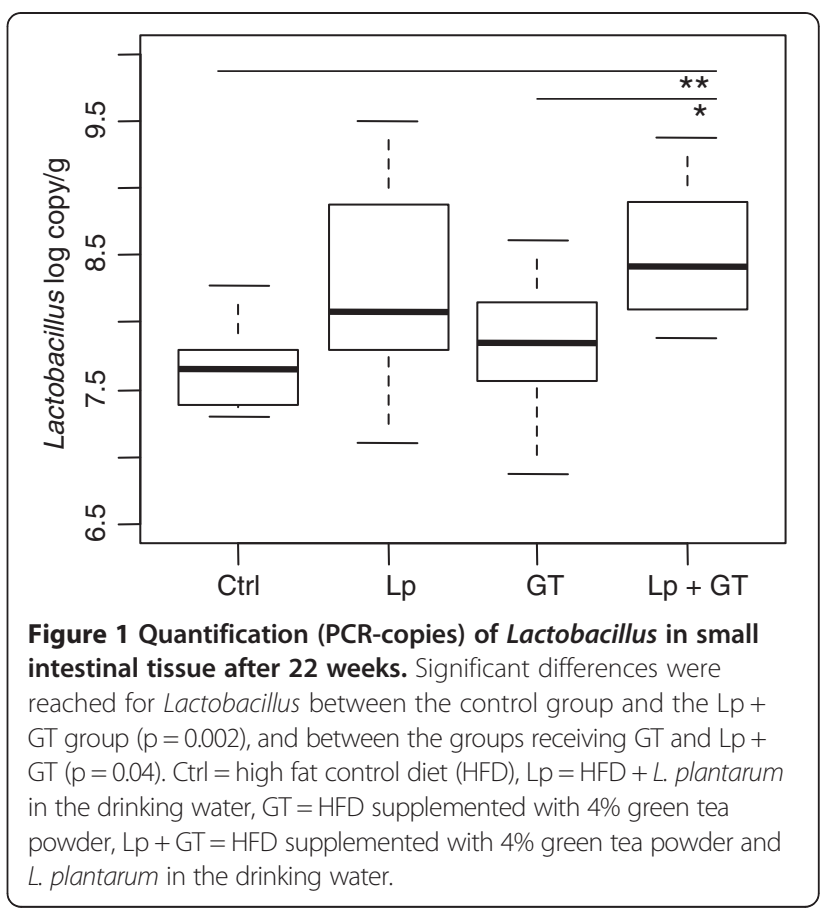

copies/g for Akkermansia were $6.75 \pm 0.27$ (control), $6.85 \pm 0.75(\mathrm{Lp}), 6.97 \pm 0.52(\mathrm{GT})$ and $7.09 \pm 0.43(\mathrm{Lp}+$ $\mathrm{GT})$. For the total bacteria the mean values of bacterial copies were $8.66 \pm 0.38$ (control), $8.81 \pm 0.53$ (Lp), $9.02 \pm$ $0.40(\mathrm{GT})$, and $9.09 \pm 0.38(\mathrm{Lp}+\mathrm{GT}) \log$ copies/g. No Enterobacteriaceae could be detected, except for in one individual (data not shown).

T-RFLP was used for analyzing the diversity of the gut microbiota. When using restriction endonuclease $M s p I$ the number of T-RFs varied between the animals and there was a significant difference in diversity based on the number of T-RFs among the four groups $(\mathrm{p}<0.001)$. The median values of the peak numbers of the groups were 3.5, 6.0, 6.5 and 8.0 for control, Lp, GT and Lp + GT respectively. Pair wise comparison of the groups revealed significant differences between control and GT $(\mathrm{p}<0.05)$, and between control and Lp + GT $(\mathrm{p}<0.001)$. Shannon $\left(\mathrm{H}^{\prime}\right)$ as well as Simpsons's diversity index (D) showed a significant difference among the four groups ( $\mathrm{p}=0.007$ and $\mathrm{p}=0.006$ respectively). Pair-wise comparison showed that the Lp + GT group had a significantly more diverse microbiota than the control group ( $\mathrm{p}=$ 0.008) and the GT group according to the Shannon diversity index $(p=0.04)$ (Figure 2$)$. According to the Simpson's diversity index the Lp group had a significantly higher diversity than the GT group $(\mathrm{p}=0.04)$ (data not shown). A T-RF corresponding to L. plantarum DSM 15313 was found in 5 individuals in the Lp group and in 4 individuals in the $\mathrm{Lp}+\mathrm{GT}$ group. In order to identify some of the T-RFs in the T-RFLP profiles, the two mice with the highest number of T-RFs in 


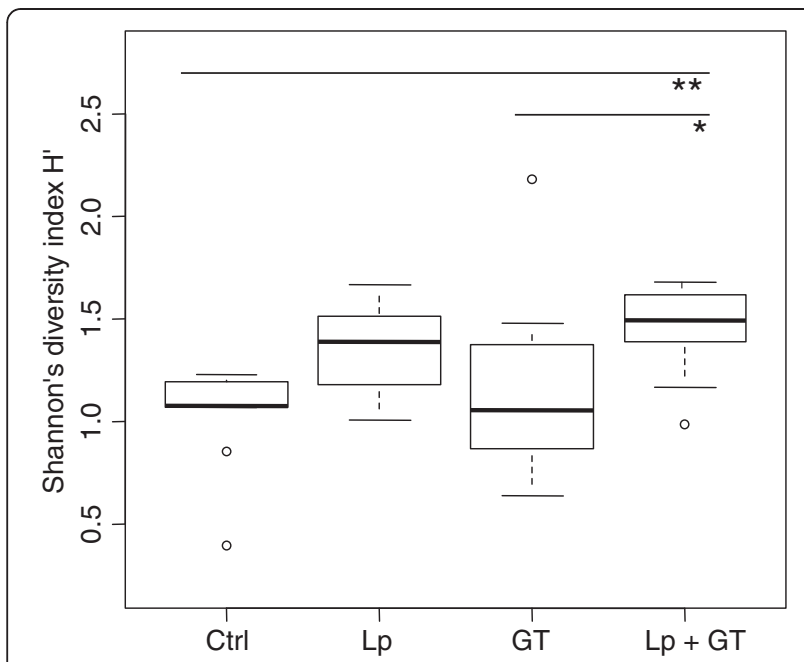

Figure 2 Bacterial diversity in the small intestine after 22 weeks. The data is based on T-RFLP-profiles and Msp1 digestion. The area of each peak, expressed as the proportion of the total area, was used for calculation of the Shannon diversity index. Control vs. $L p+G T(p=0.008), G T$ vs. $L p+G T(p=0.04)$

the control and Lp + GT group were selected for bacterial cloning. The obtained sequences were edited and 55 sequences were analyzed and compared to the closest matches in the RDP database [36] (Table 1). Fiftyone out of fiftyfive clones belonged to the phylum Firmicutes. Within Firmicutes, sequences similar to the family Erysipelotrichaceae were dominating. These sequences were most similar to the genus Allobaculum, but the similarity was only $89 \%$. In the mouse from the Lp + GT group, $25.9 \%$ of the clones were identified as Lactobacillus compared to only $3.6 \%$ from the control mouse. Clones identified as Lactobacillus were most similar to sequences belonging to Lactobacillus reuteri and Lactobacillus intestinalis. Due to differences between the theoretical and the actual sizes of T-RFs of the clones no attempt was made to identify the T-RFs except for Akkermansia and the given L. plantarum strain which showed fragments length of 265 and 568 bp, respectively. A comparison was made between T-RFLP and the numbers of copies in the qPCR. The mean copy value for Akkermansia obtained in the qPCR for the T-RFs detected in the T-RFLP was $\log 7.28 \pm 0.52$ compared to a mean of $\log 6.75 \pm 0.27$ for copy number that was not detected by T-RFLP. No microbial analyses of the small intestine were performed at 11 weeks.

\section{Caecum weight and microbiota}

After 11 weeks, the caecum weights were significantly higher in mice from the GT groups compared to mice in the control and Lp groups (control: $0.126 \pm 0.006$, Lp: $0.133 \pm 0.007$ GT: $\quad 0.225 \pm 0.015, \quad$ Lp + GT: $\quad 0.229 \pm$ $0.015 \mathrm{~g})$. After 22 weeks, the difference in caecum weights was even more pronounced (control: $0.125 \pm$ 0.013, Lp: $0.148 \pm 0.008$, GT: $0.291 \pm 0.027, \quad$ Lp + GT: $0.332 \pm 0.022 \mathrm{~g}$ ). The caecum microbiota was analyzed by cultivation and by T-RFLP after 11 and 22 weeks. The viable count of lactobacilli in the caecum content was significantly higher in the Lp group $(\mathrm{p}<0.01)$ than

Table 1 Direct identification of 16S rRNA genes from small intestinal tissue by PCR-amplification, cloning and sequencing

\begin{tabular}{|c|c|c|c|c|}
\hline Phylum & Accession no. & Closest type strain & Group (No of clones) $^{a}$ & Similarity (\%) \\
\hline \multicolumn{5}{|c|}{ Firmicutes } \\
\hline & X76329 & Lactobacillus pontis (T) & Ctrl (1) & 95.5 \\
\hline & AJ306299 & Lactobacillus intestinalis (T) & $\mathrm{Lp}+\mathrm{GT}(3)$ & $99.2-99.5$ \\
\hline & L23507 & Lactobacillus reuteri (T) & $\mathrm{Lp}+\mathrm{GT}(3)$ & $95.3-95.7$ \\
\hline & X94229 & Lactobacillus oris (T) & $L p+G T(1)$ & 95.1 \\
\hline & M59230 & Eubacterium biforme $(\mathrm{T})$ & $L p+G T(1)$ & 89.5 \\
\hline & AJ417075 & Allobaculum stercoricanis (T) & Ctrl (24) Lp + GT (17) & $89.1 \sim 89.4$ \\
\hline & X73447 & Clostridium irregulare $(\mathrm{T})$ & Ctrl (1) & 96.1 \\
\hline \multicolumn{5}{|c|}{ Verrucomicrobia } \\
\hline & AY271254 & Akkermansia muciniphila (T) & Ctrl (1) & 99.7 \\
\hline \multicolumn{5}{|c|}{ Proteobacteria } \\
\hline & DQ422859 & Desulfovibrio bizertensis (T) & $L p+G T(1)$ & 88.8 \\
\hline \multicolumn{5}{|c|}{ Actinobacteria } \\
\hline & AF292373 & Olsenella uli (T) & $L p+G T(1)$ & 94.4 \\
\hline & AB042288 & Propionibacterium acnes $(\mathrm{T})$ & Ctrl (1) & 100 \\
\hline
\end{tabular}

${ }^{\mathrm{a}} \mathrm{Ctrl}=$ high fat control diet (HFD), Lp + GT + HFD supplemented with $4 \%$ green tea powder and L. plantarum in the drinking water. Numbers within parentheses denote the number of clones in each mouse. ${ }^{b}$ Denotes highest sequence similarity to a type strain (T) found in the Ribosomal data base project Release 10 (http://rdp.cme.msu.edu/). 
in the control group at 11 weeks while the Lp+GT group had significant more lactobacilli than control $(\mathrm{p}<$ 0.01 ) and the GT-group $(\mathrm{p}<0.05)$ after 22 weeks (see Additional file 6). L. plantarum DSM 15313 was found at both 11 and 22 weeks in the two groups fed L. plantarum. L. plantarum could be reisolated from $77 \%$ and $100 \%$ of the mice in the Lp + GT and Lp groups, respectively (data not shown). No significant difference in the viable count of Enterobacteriaceae was seen after 11 weeks in the three treatment groups compared to the control. After 22 weeks, the viable count of Enterobacteriaceae had decreased below the detection limit in more than $40 \%$ of the animals and no statistical analysis was made (data not shown).

T-RFLP analysis of the caecum content generated in total 72 different T-RFs after 11 weeks and 82 T-RFs after 22 weeks in the T-RFLP-profile using MspI. At 11 weeks the GT group had significantly more T-RFs than the control when using MspI $(\mathrm{p}<0.01)$. For $A l u \mathrm{I}$ digestions, both the GT group and the Lp + GT group had significantly more T-RFs than the control group $(\mathrm{p}<0.05)$. After 22 weeks there were no differences compared to the control with either MspI or AluI (data not shown). Shannon and Simpson diversity indices were calculated for each sample using the relative T-RF area. After 11 weeks both the Shannon and the Simpson indices showed a significantly higher diversity of the microbiota in the GT group compared to the control when using Alu1 digestion for the former and either MspI or Alu1 digestion for the later (see Additional file 7). After 22 weeks, no significant differences in the bacterial diversity of the caecum content could be seen between the treatment groups and the control (see Additional file 7). In order to perform a putative identification of T-RFs from the caecum content, a pure culture of L. plantarum DSM 15313 was analyzed by T-RFLP, showing a single T-RF of 568 base pairs. This T-RF was not found in the control group or in the GT group but in all animals of the Lp group and in 75\% of the mice in the Lp + GT group. Also, a T-RF (265 bp) corresponding to Akkermansia was found in 27 mice of 29 after 11 weeks and in 40 mice of 43 after 22 weeks.

\section{Adiposity}

Body weight gain and relative body fat content was significantly reduced in mice of the GT groups compared to control mice (Figure 3A, C). A supplement of Lp had no significant effect on body weight or body fat content. The mean energy intake was higher in mice fed GT compared to mice fed a diet without GT (Figure 3B). In addition, periovarian white adipose tissue depots (Figure 3E) and circulating leptin (Figure 3F) were strongly reduced in mice receiving GT. No significant difference in lean body mass was observed between groups (Figure 3D). The amount of Akkermansia in the small intestine correlated negatively with body fat content $(\mathrm{rho}=-0.43 ; \mathrm{p}=0.04)$, periovarian white adipose tissue (rho $=-0.43 ; \mathrm{p}=0.03$ ) as well as plasma leptin (rho $=-0.45 ; \mathrm{p}=0.03)$. The total amount of bacteria in the small intestine correlated negatively with periovarian white adipose tissue (rho $=-0.41 ; \mathrm{p}=0.04$ ) and showed a tendency towards a negative correlation with total body fat ( $\mathrm{rho}=-0.41 ; \mathrm{p}=0.07$ ) and plasma leptin ( $\mathrm{rho}=-0.35$; $\mathrm{p}=0.09$ ). The mean faecal TAG excretion was significantly elevated in the GT groups compared to control (control: $0.08 \pm 0.01, \mathrm{Lp}: 0.18 \pm 0.05$, GT: $0.27 \pm 0.04, \mathrm{Lp}+$ GT: $0.31 \pm 0.04 \mathrm{mg} / \mathrm{mouse} / 24 \mathrm{~h})$. The total amount of faeces was not significantly different between the groups although a tendency towards increased excretion was observed in the GT groups compared to the control group (ctrl: $0.27 \pm 0.02$, Lp: $0.30 \pm 0.04$, GT: $0.39 \pm 0.06$, Lp + GT: $0.40 \pm 0.06 \mathrm{mg} / \mathrm{mouse} / 24 \mathrm{~h}$ ).

\section{Blood glucose control}

Oral glucose tolerance tests were performed at week 8 and week 21. At week 8, the mice in the two GT groups had a significantly increased insulin response compared to control mice (Figure 4B). Also, the Lp + GT group had a significantly increased glucose response compared to the control and the Lp group (Figure 4A). The same tendencies were seen at week 21, however, the differences did no longer reach statistical significance (Additional file 8). An insulin tolerance test was performed at week 15. No significant differences were observed between any of the groups (Figure $4 \mathrm{C}$ ). After 22 weeks, fasting plasma glucose, insulin and fructosamine were lower in the mice from the GT groups, while insulin and fructosamine were significantly lower already after 11 weeks (Table 2). In addition, after 22 weeks, GT resulted in a lower HOMA index of insulin resistance (Figure 4D). The amount of Akkermansia in the small intestine correlated negatively to plasma insulin ( $r h o=-0.47 ; \mathrm{p}=0.03$ ) and there was also a tendency towards a negative correlation between the total amount of bacteria and plasma insulin (rho$0.35 ; \mathrm{p}=0.07)$. No differences in plasma glucose or insulin were observed between the groups at the initiation of the study (data not shown).

\section{Lipid metabolism}

Both the GT and Lp + GT groups had significantly lower plasma TAG compared to control after 22 weeks (Table 2). No differences in plasma TAG were observed at the start of the study. Liver weights were significantly lower in mice from both GT groups compared to control mice after both 11 and 22 weeks (Figure 5A and B). The liver weight was also significantly lower in the Lp + GT group compared to the Lp group. Also the liver TAG 
A

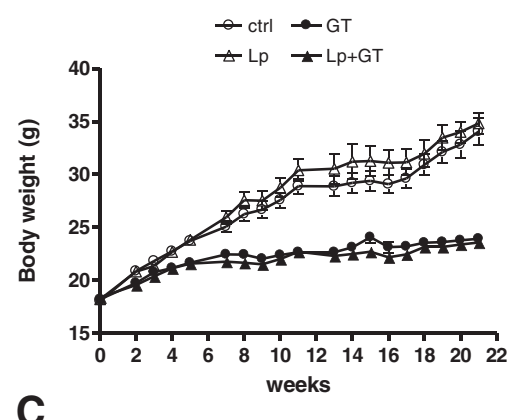

。

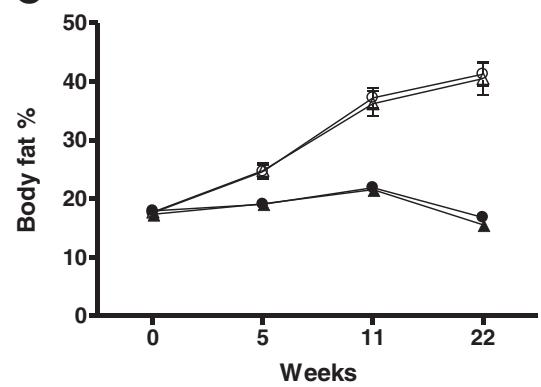

E

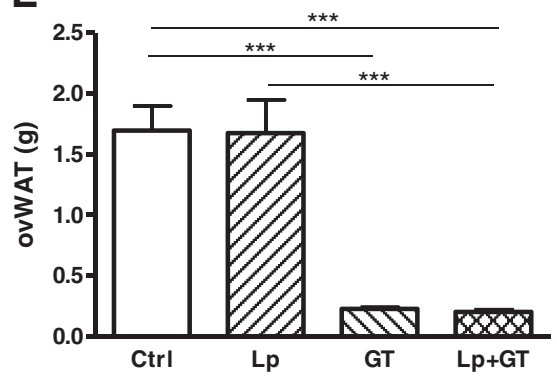

B

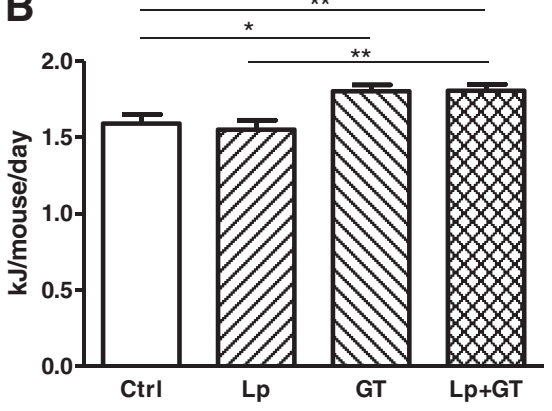

D

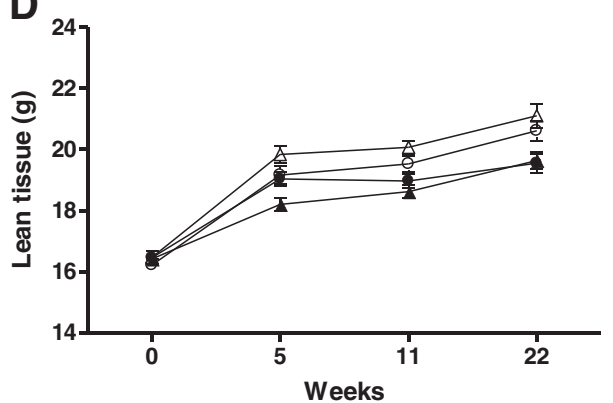

$\mathbf{F}$

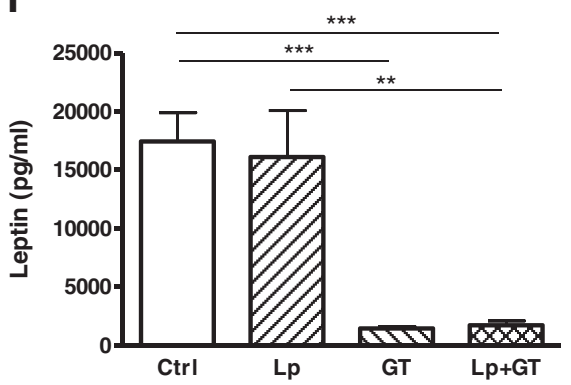

Figure 3 Decreased adiposity in mice fed a diet supplemented with green tea. (A) Weekly body weight registration during the 22 week study. (B) Average energy intake calculated as KJ/mouse/day. (C) Relative body fat content (\%) recorded using DEXA scan technique at week 0, 5, 11 and 22. (D) Lean body mass measured with DEXA at 0, 5, 11 and 22 weeks. (E) Periovarian white adipose tissue weight and (F) plasma leptin concentration after 22 weeks on the different diets. Ctrl = high fat control diet (HFD), Lp = HFD + L. plantarum in the drinking water, GT = HFD supplemented with $4 \%$ green tea powder, LP + GT $=$ HFD supplemented with $4 \%$ green tea powder and L. plantarum in the drinking water. Data are means \pm SEM $n=21$ at 11 weeks and $n=9-11$ at 22 weeks. ${ }^{*} p<0.05,{ }^{* *} p<0.01,{ }^{* * *} p<0.001$.

content related to liver mass was decreased in the groups fed GT and showed the same picture regarding significance as the liver weight (Figure $5 \mathrm{C}$ and $\mathrm{D}$ ). Between 11 and 22 weeks, there was a general increase in liver TAG accumulation in all groups but the GT group. Moreover, the liver enzyme ALT was decreased in plasma from mice in the GT groups compared to the mice in the control group (Figure 5E and F). However, plasma ALT was generally higher in all groups after 22 weeks compared to 11 weeks. After 22 weeks the mRNA expression of the lipogenic transcription factors SREBP1C and PPAR $\gamma$ was significantly down-regulated in both groups of mice fed GT (Figure 6A and B). The mRNA expression of the lipogenic enzyme ACC was decreased only in mice receiving GT compared to control, and the same trend was observed for the expression of FAS mRNA (Figure 6C and D). The hepatic mRNA expression of PPAR $\alpha$, PGC- $1 \alpha$, CD36, ACADL, LXR, PXR, chREBP, XBP1, PEPCK, CREB and GK is shown in the Additional file 9. A significant difference in the mRNA expression of PPAR $\alpha$, which plays a role in the control of fatty acid oxidation, was observed between mice in the GT group compared to control mice at 22 weeks. Also, a decreased mRNA expression of CD36 and LXR, both involved in the control of lipogenesis, was observed in mice from the $\mathrm{Lp}+\mathrm{GT}$ group compared to control, after 11 and 22 weeks respectively (Additional file 9). The amount of Akkermansia correlated negatively with the TAG content in the liver (rho = $-0.44 ; \mathrm{p}=0.03$ ) and there was also a tendency towards a negative correlation between the total amount of bacteria and liver TAG (rho-0.36; $\mathrm{p}=0.07$ ). 

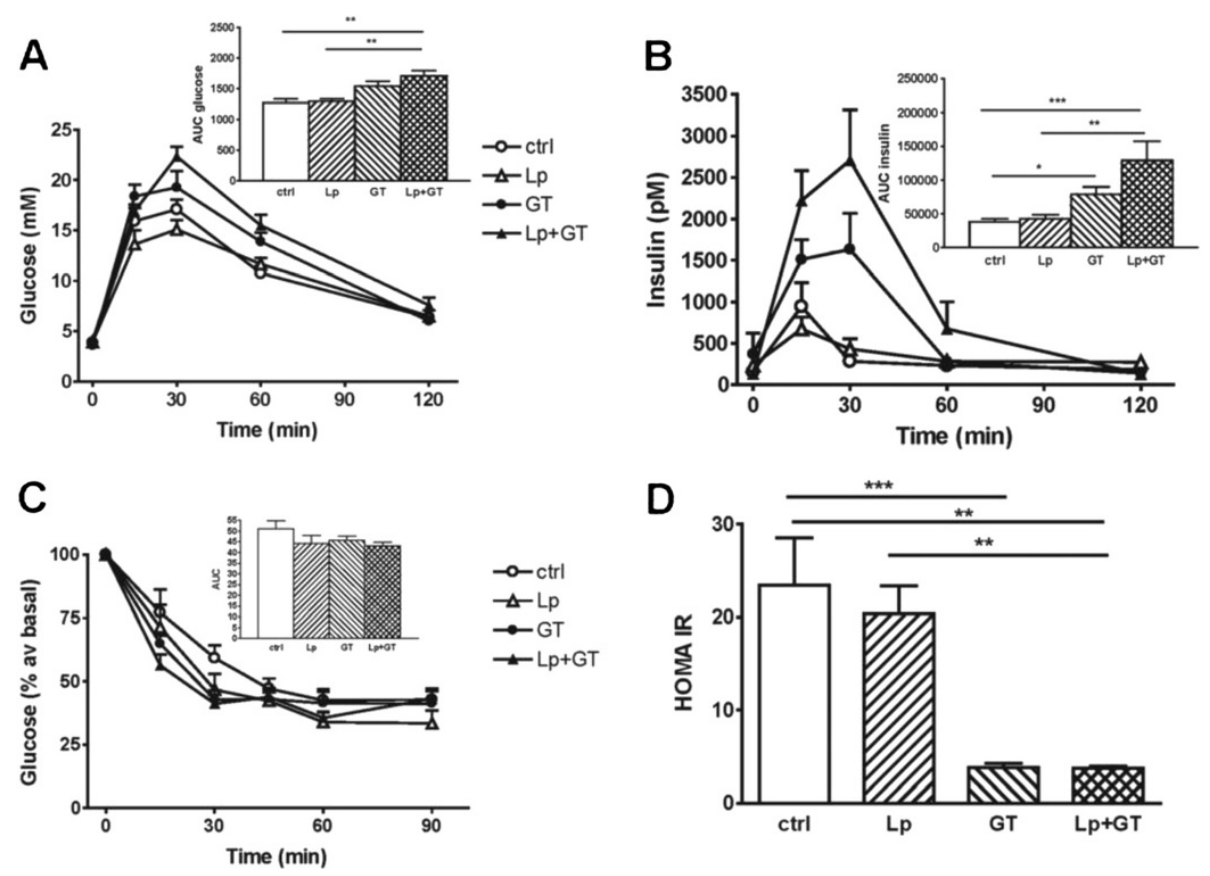

Figure 4 Altered glucose and insulin tolerance by supplementing the diet with green tea. (A) Plasma glucose and (B) insulin concentrations in an oral glucose tolerance test performed at week 8. Mean values and SEM for 11 mice in each group. (C) Plasma glucose expressed as \% of basal after an intraperitoneal injection of insulin at week 15. Mean values and SEM for 9-11 mice in each group. No differences were detected between any of the four groups. The areas under the curves (AUC) are shown in the insets (D) HOMA-IR index at week 22 . The index was calculated by multiplying fasting glucose $(\mathrm{mM})$ and fasting insulin $(\mu \mathrm{U} / \mathrm{ml})$ divided by 22.5 . Ctrl = high fat control diet $(H F D), L p=H F D+L$. plantarum in the drinking water, GT = HFD supplemented with $4 \%$ green tea powder, $L p+G T=H F D$ supplemented with $4 \%$ green tea powder and $L$. plantarum in the drinking water. Data are means \pm SEM for $9-11$ mice/group. ${ }^{*} p<0.05,{ }^{* *} p<0.01,{ }^{* * *} p<0.001$.

Table 2 Plasma profile after indicated time of dietary treatment

\begin{tabular}{|c|c|c|c|c|c|}
\hline & Week & Ctrl & Lp & GT & Lp + GT \\
\hline \multirow[t]{2}{*}{ Glucose (mM) } & 11 & $7.3 \pm 0.4$ & $8.2 \pm 0.6$ & $7.4 \pm 0.7$ & $7.5 \pm 0.5$ \\
\hline & 22 & $9.3 \pm 0.5 a \#$ & $9.5 \pm 0.7 a$ & $6.0 \pm 0.4 b$ & $7.1 \pm 0.3 b$ \\
\hline \multirow[t]{2}{*}{ Insulin (pM) } & 11 & $289 \pm 48 a$ & $403 \pm 50 a$ & $177 \pm 12 b$ & $169 \pm 12 b$ \\
\hline & 22 & $387 \pm 72 a$ & $353 \pm 58 a$ & $99 \pm 6 b^{*}$ & $100 \pm 4 b^{*}$ \\
\hline \multirow[t]{2}{*}{ Fructosamine $(\mu \mathrm{M})$} & 11 & $535 \pm 25 a$ & $629 \pm 45 a$ & $429 \pm 23 b$ & $545 \pm 41 b$ \\
\hline & 22 & $606 \pm 18 a \S$ & $582 \pm 39 a$ & $521 \pm 16 b \#$ & $518 \pm 21 b$ \\
\hline \multirow[t]{2}{*}{ Cholesterol (mM) } & 11 & $4.2 \pm 0.24 a$ & $4.3 \pm 0.22$ & $4.7 \pm 0.22$ & $4.8 \pm 0.08 b$ \\
\hline & 22 & $5.2 \pm 0.3 a \S$ & $5.0 \pm 0.24 a$ & $3.9 \pm 0.08 b^{*}$ & $4.0 \pm 0.18 b^{*}$ \\
\hline \multirow[t]{2}{*}{ TAG (mM) } & 11 & $0.41 \pm 0.04 a$ & $0.42 \pm 0.07$ & $0.29 \pm 0.03 b$ & $0.31 \pm 0.02$ \\
\hline & 22 & $0.48 \pm 0.05 a$ & $0.40 \pm 0.05 a$ & $0.30 \pm 0.02 b$ & $0.32 \pm 0.03 b$ \\
\hline \multirow[t]{2}{*}{ NEFA (mM) } & 11 & $0.57 \pm 0.02 a$ & $0.59 \pm 0.04 a$ & $0.47 \pm 0.03 b$ & $0.52 \pm 0.03 a b$ \\
\hline & 22 & $0.52 \pm 0.03$ & $0.55 \pm 0.05$ & $0.47 \pm 0.01$ & $0.49 \pm 0.03$ \\
\hline \multirow[t]{2}{*}{ Adiponectin $(\mu \mathrm{g} / \mathrm{ml})$} & 11 & $18.1 \pm 1.3$ & $17.6 \pm 1.0$ & $14.7 \pm 1.6$ & $14.8 \pm 1.7$ \\
\hline & 22 & $18.4 \pm 1.5 a b$ & $18.8 \pm 0.9 a$ & $15.3 \pm 0.7 b$ & $15.7 \pm 0.8 b$ \\
\hline
\end{tabular}



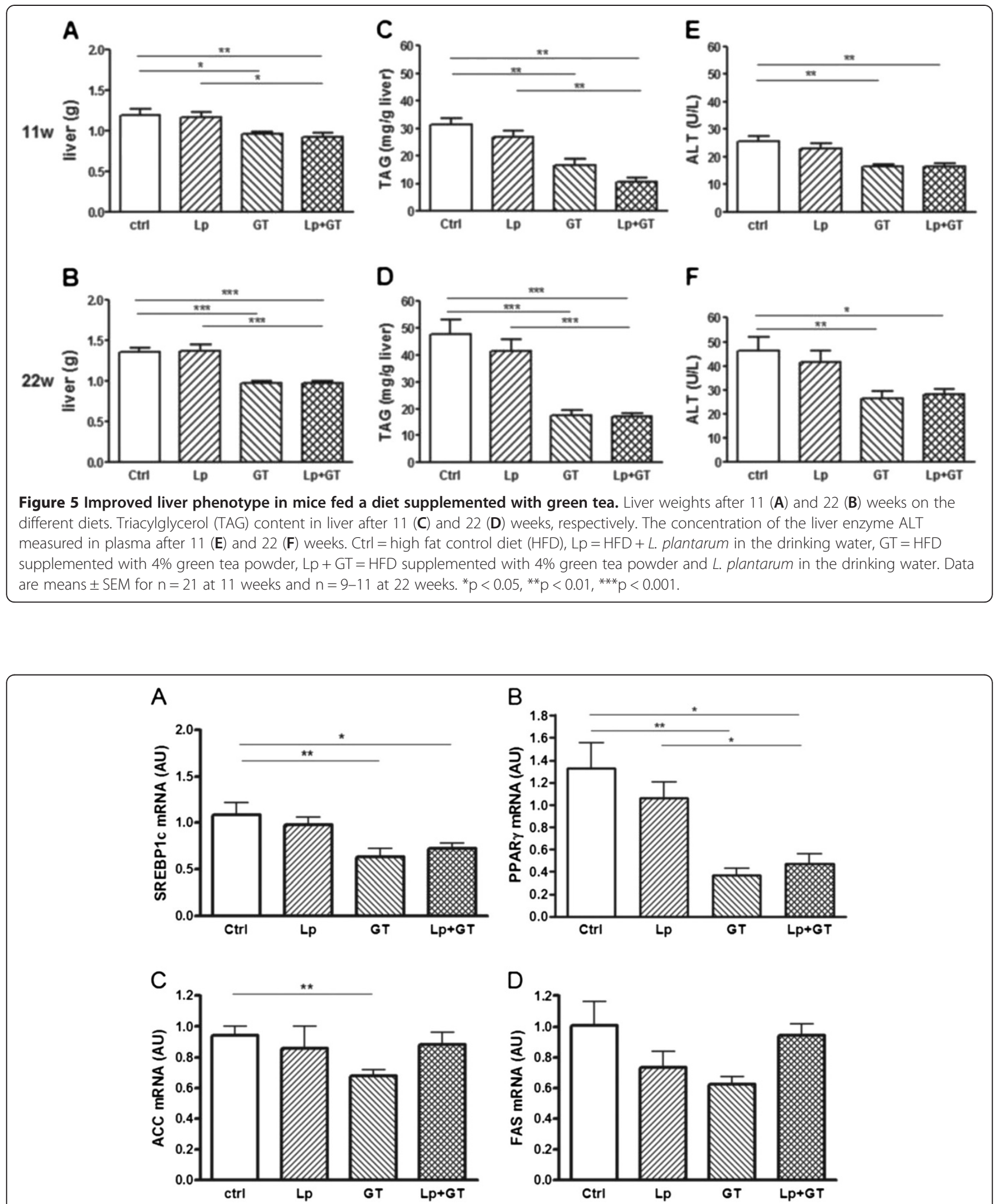

Figure 6 Decreased lipogenic gene expression in liver of mice fed a diet supplemented with green tea. Hepatic mRNA expression of sterol regulatory-binding protein 1c (SREBP1C, A), peroxisome proliferator-activated receptor $\mathrm{Y}$ (PPARY, B), acetyl CoA carboxylase (ACC, C) and fatty acid synthase (FAS, D) was quantified with real-time PCR after 22 weeks of the different diets. Ctrl = high fat control diet $(H F D), L p=H F D+L$. plantarum in the drinking water, GT = HFD supplemented with $4 \%$ green tea powder, Lp + GT $=$ HFD supplemented with $4 \%$ green tea powder and $L$. plantarum in the drinking water. Data are means \pm SEM. $n=9-11$ at 22 weeks. ${ }^{*} p<0.05,{ }^{* *} p<0.01$. 


\section{Cholesterol metabolism}

Plasma cholesterol was significantly higher in the Lp + GT group after 11 weeks but after 22 weeks it was significantly lower in both GT groups compared to control (Table 2). No differences in plasma cholesterol were observed between the groups at the start of the study (data not shown). The liver cholesterol content was decreased in both groups receiving GT after 11 weeks, but after 22 weeks it was also decreased in the Lp group compared to control (Figure 7A and B). Liver cholesterol decreased over time in all groups but Lp + GT, which showed unchanged cholesterol content between 11 and 22 weeks. After 11 weeks, the key enzyme in cholesterol synthesis, HMGCoA reductase was upregulated in the Lp + GT group but no significant changes in the mRNA expression of the cholesterol-regulating transcription factor SREBP2 were observed between the groups (Figure 7C and E). However, after 22 weeks, HMGCoA reductase was significantly up-regulated in the $\mathrm{Lp}+\mathrm{GT}$ group compared to the other groups (Figure 7D) and SREBP2 was upregulated compared to control and Lp (Figure 7F). The hepatic expression of SR-B1, LDLR and CYP7A1, genes involved in reverse cholesterol transport, is shown in Additional file 9. SR-B1, an HDL receptor, was significantly upregulated in mice fed GT compared to control mice. The mRNA expression of the LDL receptor was down-regulated in mice in the GT group compared to control mice but the significance was eliminated with addition of Lp. Total cholesterol excretion was increased in the GT groups compared to control (control: $0.64 \pm 0.1$, Lp: $0.65 \pm 0.11$, GT: $1.56 \pm 0.11$, Lp + GT: $1.55 \pm 0.18 \mathrm{mg} / \mathrm{mouse} / 24 \mathrm{~h})$. The hepatic cholesterol content and plasma cholesterol correlated negatively with the total amount of bacteria (rho $=-0.43 ; \mathrm{p}=$ 0.04 and rho $=-0.44 ; \mathrm{p}=0.04$ respectively).

\section{Markers of inflammation}

Circulating PAI-1 was significantly decreased in mice in the Lp + GT group compared to mice in the Lp group $(\mathrm{p}<0.05)$ after 22 weeks but not after 11 weeks (Figure 8A and B). Plasma PAI-1 was also negatively correlated with Akkermansia ( $\mathrm{rho}=-0.49 ; \mathrm{p}=0.03$ ) at 22 weeks. The cytokines IL- 6 and MCP-1 were analyzed in the same multiplex assay as PAI-1, but the plasma concentrations were below the detection limit. The hepatic mRNA expression of MCP-1 and TNF- $\alpha$ showed no differences after 11 weeks but with a tendency of decreased MCP-1 in the Lp + GT group (Figure $8 \mathrm{C}$ and E). After 22 weeks MCP-1 decreased in the Lp + GT group compared to the Lp group and TNF- $\alpha$ decreased in the Lp + GT group compared to both the control and the GT group $(\mathrm{p}<0.05)$ (Figure 8D and F). The hepatic mRNA expression of PAI-1, TLR4, MyD88 and F4-80 is shown in Additional file 9. A significant difference in the expression of TLR4 was observed between mice in GT and Lp + GT groups. Moreover, the spleen weights were decreased in

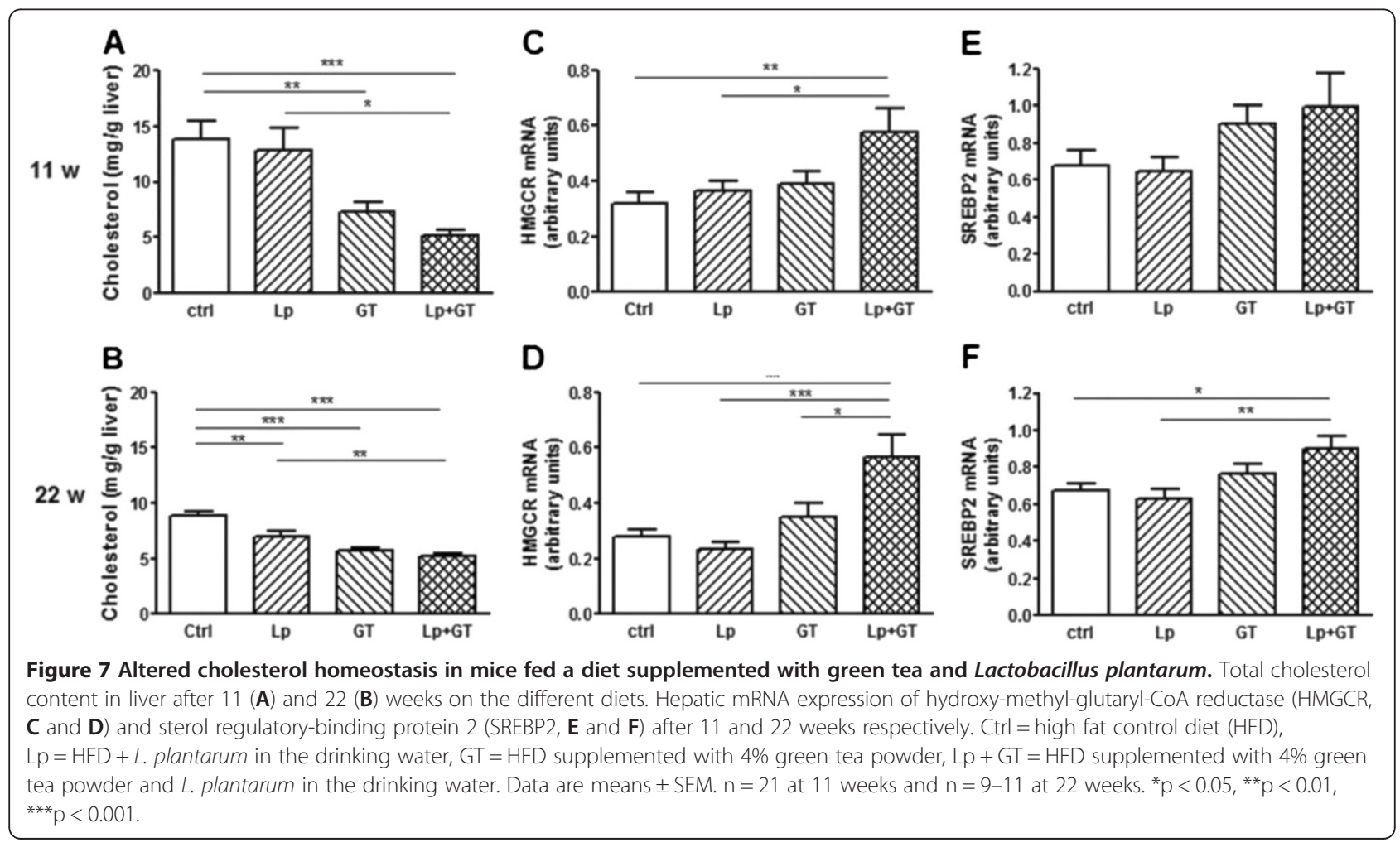




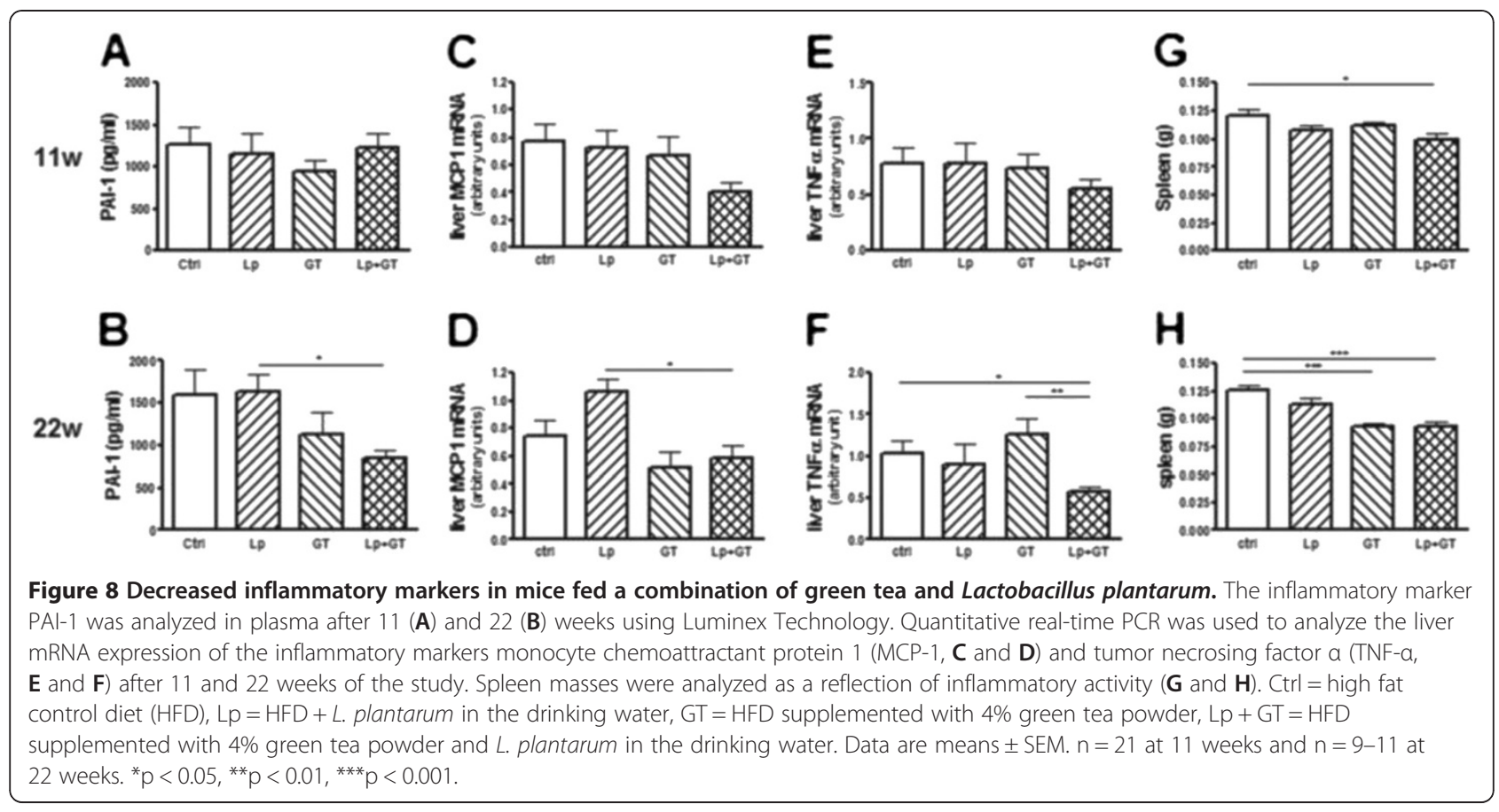

the Lp + GT group compared to control group after 11 weeks $(\mathrm{p}<0.05)$ (Figure 8G), and after 22 weeks, mice in the two GT groups had significantly smaller spleens compared to the control group $(\mathrm{p}<0.001)$ (Figure $8 \mathrm{H})$.

\section{Multivariate data analysis}

A PCA of the metabolic data was performed for the four groups of mice. The mice fed green tea clustered separately from the control and Lp groups (data not shown). An $x / y$ plot showed that most of the variability in the model was explained by body fat (data not shown).

A PCA was applied on the T-RFLP data of the small intestine and the caecum, respectively, combined with the metabolic parameters, in order to reveal differences and similarities between and within the four groups. The combined data for the small intestine showed that mice in the GT and Lp + GT groups displayed more similarity to each other compared to the control and Lp groups (data not shown). The combined caecum data indicate that the mice in the Lp group clustered together while the mice in the three other groups were more different from each other (data not shown). A PLS analysis of the combined data was then performed to reveal any correlation between the T-RFs, i.e. microbiota, and the metabolic parameters.. The obtained PLS loadings bi-plots showed that the control and the Lp groups were separated from the GT and Lp + GT groups (Figure 9A and B). Variables located closely together are more likely to have a positive correlation, while variables far away from each other, either along the first or the second principal component, are more likely to be negatively correlated.
The T-RFs having the most influence on the model are indicated with their fragment size, and in the small intestine a high abundance of T-RFs 118 and 184 correlated positively to the increase of the metabolic markers while T-RF 271 was negatively correlated (Figure 9A). In the ceacum, T-RFs 270 and 307 correlated negatively with all the metabolic markers except SR-B1 expression and caecum weight while T-RF 568 and 497 correlated positively with the same data (Figure 9B). The T-RF 568 corresponds to the given strain $L$. plantarum DSM 15313 and the positive correlation is probably due to the high abundance of this strain in the Lp group.

\section{Discussion}

The present study shows that green tea powder (GT) alone, or in combination with L. plantarum DSM 15313 (Lp), exerts beneficial metabolic effects in C57BL/6J mice fed an HFD. These results are in agreement with and an extension of previous studies of metabolic effects of green tea in rodents. However, in contrast to most previous studies, in which the green tea extract or the phenolic constituent epigallocatechin gallate (EGCG) has been evaluated, we have here studied the effect of whole tea leaves milled to a powder, which is suggested to contain higher quantities of polyphenols compared to a water extract of green tea [45]. Indeed, our analysis of the green tea powder showed a higher amount of catechins compared to a water extract from the same green tea powder. The present study additionally shows that when a tannase active strain of $L$. plantarum was 


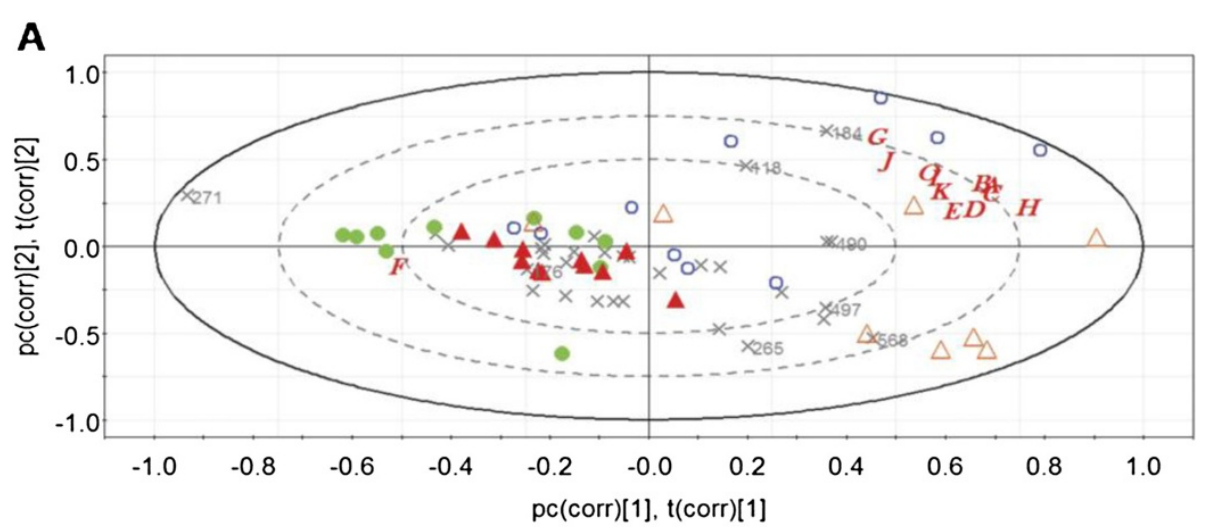

B

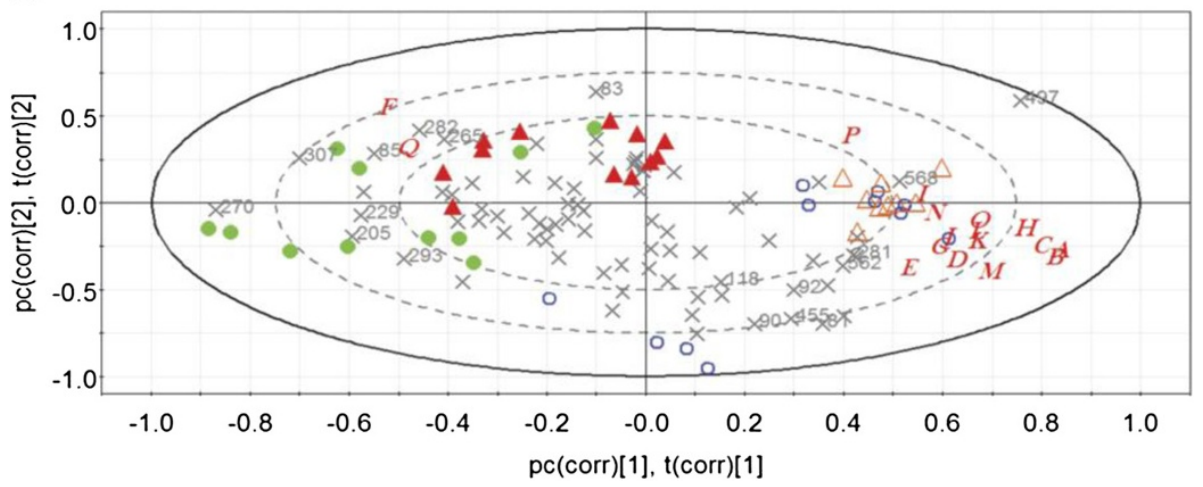

Figure 9 PLS plot of the intestinal microbiota and analyzed parameters of individual mice at 22 weeks. Projections to latent structures (PLS) loadings biplot of the microbiota (T-RFs of the T-RFLP profile) and the physiological parameters (A through Q) of the individual mice in the small intestine (A) and caecum (B). For the small intestine PC1 explained 25.6\% and PC2 15.6\% of the variation. For caecum the PC1 explained 26.4\% and PC2 16.4\% of the variation. Blue open circle represents mice in the control group (Ctrl); orange open triangle for the group supplemented with L. plantarum DSM 15313 (Lp); green dot for the group supplemented green tea (GT); red triangle for the group supplemented L. plantarum DSM 15313 and green tea $(L p+G T)$. Letters denote metabolic parameters, A, body weight; B, body fat content; C, periovarian white adipose tissue; $D$, liver weight; $E$, spleen weight; $F$, caecum weight; $G$, liver cholesterol; $H$, liver TAG; I, plasma ALT; J, plasma cholesterol; K, plasma insulin; L, plasma glucose; M, plasma leptin; N, PPARa mRNA; O, PPARY mRNA; P, CD36 mRNA; Q, SR-B1 mRNA. Symbol X denotes T-RFs. T-RFs having the biggest influence on the model are marked by numbers indicating the fragment size.

supplemented to the GT-diet (Lp + GT), both the load of lactobacilli and the bacterial diversity increased significantly in the small intestine. It seems likely that the increase in diversity was due to effects exerted by the given Lactobacillus strain in combination with GT rather than just the addition of one more species to the microbiota.

The observed reduction in adiposity after green tea intake is in agreement with previous studies, including studies in HFD-fed C57BL/6J mice. Increased faecal lipid excretion is likely to be a major factor contributing to the reduced adiposity. It is known that green tea extracts possess the ability to inhibit intestinal lipases [46]. In addition to lipases, green tea catechins have been shown to inhibit glucose transporters and enzymes involved in carbohydrate digestion, raising the possibility that also carbohydrate absorption could be reduced $[47,48]$. EGCG has previously been shown to slightly increase energy content of faeces as a consequence of reduced digestibility [14]. There were indications that components of the microbiota might interfere with lipid metabolism. The amount of Akkermansia in the small intestine was shown to correlate negatively with the total body fat content, the periovarian fat depots as well as the circulating levels of leptin, suggesting a role for Akkermansia in reducing fat accumulation. Interestingly, Akkermansia muciniphila was recently shown to be increased in prebiotic-treated $o b / o b$ mice which had lower fat mass compared to control ob/ob mice [49]. In a study of pregnant women, the number of Akkermansia and Bifidobacterium was higher in women with normal weight gain compared to those with excessive weight gain [50]. Akkermansia has also been shown to be increased in normal weight and post-gastric-bypass individuals compared to obese [51]. In the present study, a negative correlation was also detected between the total number of 
bacteria and periovarian fat mass. However, it remains to be proven that the correlations point at the cause of the alterations in lipid metabolism.

In accordance with the reduced adiposity after GT intake, GT reduced hepatic lipid content and circulating levels of ALT suggesting that GT either directly, or indirectly, perhaps via an altered microbiota, ameliorates the liver damage imposed by the HFD. The involvement of an altered microbiota is supported by the negative correlation between the amount of Akkermansia and the hepatic TAG content. Ma et al. demonstrated that the probiotic mixture of different Lactobacillus and Bifidobacterium strains (labelled VSL\#3) reduced a HFD induced hepatic steatosis in C57BL6 mice [11]. On the other hand Velayudham et al. demonstrated that the same probiotic mixture did not prevent liver steatosis but modulated the progression to liver fibrosis [52]. Here, the supplement with one strain of L. plantarum did not have the capacity to reduce the hepatic TAG accumulation. SREBP-1c is a key transcription factor in hepatic lipogenesis and is partly regulated by PPAR $\gamma$ and LXR [53]. The down-regulation of the mRNA expression of SREBP-1c, PPAR $\gamma$ and LXR suggests that decreased hepatic lipogenesis contributes to the reduced hepatic lipid content observed in the mice fed GT. Also, the hepatic fatty acid transporter CD36, another lipogenic target of PPARY and LXR [53] was shown to be downregulated in the $\mathrm{GT}$ groups compared to control at 11 weeks, however, the decrease compared to control was abolished after 22 weeks. In addition, the hepatic mRNA expression of the lipogenic enzymes ACC and FAS was reduced and trended towards a diminuition, respectively, in mice fed GT alone compared to control mice, indicating a decreased de novo lipogenesis in these mice. Surprisingly, the decreased expression of the lipogenic enzymes could not be detected in mice from the Lp + GT group. The expression of the transcription factor PPAR $\alpha$ was down-regulated in mice in the GT group compared to control mice, indicating a decreased hepatic fatty acid oxidation as well. The mechanisms behind this finding need further elucidation. It should be emphasized that this is a large screening of the alterations induced by the dietary supplements and more detailed analyses, including expression at the protein level, need to be undertaken.

The choice of the present strain of probiotics is partly based upon its ability to increase the barrier effect of the gut-mucosa [54] but mainly on its ability to degrade polyphenols as tannins, and produce compounds as substituted phenyl propionic acids, phenyl valeric acids and benzoic acid derivates [26]. These compounds are more easily absorbed than longer molecular chains of phenolics, and are often also more bioactive [55,56]. They can have anti-inflammatory effects as well as antimicrobial effects.
One hypothesis is that $\mathrm{Lp}$ in the large intestine is able to convert polyphenols in GT to more easily absorbed metabolites with antioxidative effects in organs such as the liver. Generally, polyphenols possess powerful antimicrobial activities [27] which can have growth suppressing effects on many bacteria but which are better endured by others.

Feeding mice with Lp alone did not affect inflammatory markers. A reduced spleen weight was observed already after 11 weeks in the Lp + GT group and Lp + GT significantly reduced the inflammatory tone at 22 weeks, both systemically, as indicated by reduced circulating PAI-1 and decreased spleen weight [57], as well as locally in the liver, as shown by decreased mRNA expression of TNF- $\alpha$ and MCP-1. This, together with the higher number of Lactobacillus both in caecum and small intestine in the Lp + GT group support the hypothesis of Lactobacillus converting polyphenols to more active anti-inflammatory components. The higher number of lactobacilli in the Lp group and higher diversity in the GT group in the ceacum seemed not to affect the inflammatory markers at 11 weeks. The effect seen after 22 weeks might partly be explained by an increased number of bacterial taxa over time in all groups since the number of T-RFs increased at 22 weeks while no difference in diversity between the groups was seen in ceacum.

It has previously been shown that a probioticsupplemented diet decreases levels or expression of liver TNF- $\alpha$ in animal models. Ma et al. [11] found a decreased expression of TNF- $\alpha$ in the liver of HFD-fed C57BL/6 mice when the diet was supplemented with the probiotic VSL\#3 mixture. Furthermore, in an acute liver injury model in rats, TNF- $\alpha$ levels decreased in the liver when rats had been pre-treated with L. plantarum DSM 15313 before inducing liver injury [58]. Also, green tea extract alone has been shown to reduce hepatic mRNA levels of both TNF- $\alpha$ and MCP-1 as well as NFKB binding activity [59]. Additionally, a negative correlation between Akkermanisia and plasma PAI-1 was seen, indicating that Akkermansia may have a beneficial influence on the inflammatory state. It has been shown in germ-free mice inoculated with Akkermansia municiphila $\mathrm{Muc}^{\mathrm{T}}$ that the colonization altered the mucosal gene expression towards a profile involved in immune responses and cell fate, which led to the conclusion that the tested strain of Akkermansia modulated pathways involved in establishing homeostasis for basal metabolism and immune tolerance towards commensal bacteria [60].

Dietary administration of GT reduced plasma cholesterol as well as hepatic cholesterol content. The supplementation with Lp alone had a significant cholesterol-lowering effect in the liver after 22 weeks and additionally the total 
number of bacteria in the small intestine was negatively correlated with both liver and plasma cholesterol. An increased faecal excretion of cholesterol was observed in the GT groups, indicating that this is at least one of the mechanisms underlying the cholesterol-lowering effect of GT administration. EGCG as well as other polyphenols have previously been shown to inhibit cholesterol absorption in rodents $[61,62]$. The underlying mechanisms are not fully elucidated but green tea catechins have been suggested to reduce the absorption of cholesterol from the intestine by reducing the solubility of cholesterol in mixed micelles [61]. SREBP2, the major regulator in cholesterol biosynthesis, and its downstream target HMG-CoA reductase, were up-regulated when GT was combined with Lp. An explanation for the upregulated cholesterol biosynthesis might be a response to the very efficient GT-induced cholesterol excretion in an attempt of the system to restore cholesterol homeostasis. This rescue mechanism of cholesterol is further supported by the upregulation of the hepatic HDL receptor SR-B1 mRNA in the GT groups.

The lower fasting plasma glucose and insulin, resulting in a lower HOMA index, as well as the lower levels of fructosamine, mirroring the blood glucose concentration over several weeks, indicate a more insulin sensitive state in the mice fed GT. In contrast, the oral glucose tolerance test showed deteriorated glucose elimination despite increased insulin secretion in the GT groups, implying decreased oral glucose tolerance compared to the control group and the Lp group. The cause for this discrepancy is not known.

A component of the microbiota that seems to be of relevance for several of the metabolic effects studied here is Akkermansia. Akkermansia muciniphila is a newly described species which has been shown to be an efficient mucin degrader found in the intestines of humans and animals [63] and it has been associated with healthy gut mucosa $[64,65]$. However, the amount of Akkermansia in the small intestine did not differ between the groups indicating that it is not the diet per se but instead the response of the specific microbiota in an individual that might be of importance. It is clear from the present results that the dietary supplements GT and Lp exercise effects on the composition of the microbiota in both the small intestine and in caecum as well as on metabolism. However, a keyquestion that remains to be answered is whether the changes in gut-microbiota affect the metabolic markers or whether the changes in the gut-microbiota result from metabolic alterations. With the assumption that certain components of the microbiota exert metabolic effects, it is clear from the present results that the microbiota of the individual mice varied widely in spite of the fact that they are from an inbred strain. Especially the individuals of the control group differ while the dietary supplements appear to standardize the microbiota to some degree. Surprisingly, the standardization differed between the small intestine and caecum, i.e. green tea made the microbiota of the individual mice more uniform in the former while Lp did the same in the latter. The multivariate analysis revealed that certain, relatively few components of the microbiota (T-RFs) in both the small intestine and in caecum, had a considerably higher effect on the correlation model built for comparing T-RFLP-data with metabolic testparameters, some showing positive correlations and some negative. It was also clear that GT and Lp in some cases affected the abundance of these bacterial components differently. One of these critical components (T-RF) could be identified as Akkermansia. However, the fact that several correlations have been found between Akkermansia and metabolic parameters do not necessarily implicate a causal role for this taxum but at least reflects that markers for inflammation and lipid metabolism are linked to the microbiota, and especially the microbiota of the small intestine. Mice in the Lp + GT group had higher bacterial diversity in the small intestine compared to both control and the GT group. The higher diversity may as such be a positive health factor or at least a health marker. It was shown in humans that the bacterial diversity of the gut microbiota was higher in lean individuals than in obese ones [66] and that neonates with low diversity at one week of age had increased risk for developing atopic eczema at 18 months of age [67]. As expected the number of T-RFs were smaller in the small intestine compared to caecum as the sampling were done close to the pylorus. In humans, the diversity in the jejunum has been shown to be lower than in the colon [68]. The T-RFLP method was chosen here even if it has a lower resolution compared to high through-put sequencing, but it gives comparable results to pyrotag sequencing regarding diversity measures [69].

\section{Conclusions}

An extensive battery of parameters has been analyzed in the present study in order to evaluate the effects of two different dietary supplements alone and in combination on gut microbiota and metabolism. It seems clear that some of the metabolic effects described in this study were accounted for by GT alone, whereas others, notably the reduced inflammation and up-regulation of genes regulating cholesterol synthesis, were only significantly observed with the combination of Lp and GT. We propose that GT acts as a potent source for dietary polyphenols, promoting the growth of a healthy, antiinflammatory intestinal microbiota and that addition of a tannase active strain of L. plantarum results in certain synbiotic effects. In addition, certain bacterial fractions of the microbiota correlate positively or negatively with risk factors for type 2 diabetes. It is of interest to identify 
the unknown fractions and to clarify if Akkermansia or some of these unknown correlating fractions are the actual cause of the observed metabolic alterations.

\section{Additional files}

\section{Additional file 1: Nutritional composition of green tea powder. \\ Additional file 2: Composition of the experimental diets. \\ Additional file 3: Additional information about the PCR-based methods.}

Additional file 4: Primer sequences used in the qPCR for quantification of Lactobacillus, total bacteria, Enterobacteriaceae and Akkermansia in the small intestinal tissue samples.

Additional file 5: Primer sequences used in the qPCR analyses of the liver tissue.

Additional file 6: Viable count of lactobacilli in caecum of the different groups.

Additional file 7: Bacterial diversity in caecum after 11 and 22 weeks.

Additional file 8: Oral glucose tolerance test at week 21.

Additional file 9: Hepatic mRNA expression.

\section{Abbreviations}

ALT: Alanine aminotransferase; AUC: Area under curve; cfu: Colony forming units; EGCG: Epigallocatechin gallate; GT: Green tea powder; HFD: High-fat diet; HOMA: Homeostasis model assessment; IL-6: Interleukin 6; Lp: Lactobacillus plantarum; MCP-1: Monocyte chemoattractant protein 1; NEFA: Non esterified fatty acids; PAI-1: Plasminogen activator inhibitor 1; PCA: Principal component analysis; PLS: Partial Least Squares Projections to Latent Structures; qPCR: Quantitative PCR; RAPD: Random amplified polymorphic DNA; T-RF: Terminal restriction fragment; T-RFLP: Terminal restriction fragment length polymorphism; TAG: Triacylglycerol.

\section{Competing interests}

The authors declare that they have no competing interests.

\section{Authors' contributions}

UA participated in planning and coordinating the study, conducted in vivo experiments, collected data, performed data analysis, interpreted data and drafted the manuscript. CO participated in the planning of the study, microbial analysis, interpretation of data and in writing the manuscript. JX performed microbial analysis, the statistical correlations analysis and PCA analysis of the microbiota and participated in the manuscript preparation. CF participated in the planning of the study, data collection and critical review of the manuscript. SL collected data and performed data analysis. KS participated in the planning of the study, data collection and critical review of the manuscript. SA participated in the planning of the study. $\mathrm{CH}$ participated in the planning of the study, interpretation of the data and critical review of the manuscript. GM conceived the hypothesis, planned the study, interpreted data and participated in the writing of the manuscript. KB conceived the hypothesis, planned and coordinated the study, collected data, interpreted data and drafted the manuscript. All authors read and approved the final version of the manuscript.

\section{Acknowledgements}

We want to thank Martin Berntsson at Umetrics (Umeå, Sweden), for help with the SIMCA software and Dr Fredrik Nilsson and Helene Jacobsson at the Competence Centre for Clinical Research, Region Skåne (Lund, Sweden) for statistical analysis. We acknowledge Birgitta Danielsson for technical assistance. This study was supported by the Lund University Antidiabetic Food Center, a VINNOVA VINN Excellence center, the Swedish Research council (project no 11284 to C.H.), the Swedish Diabetes Association, A. Påhlsson Foundation (C.H, K.B), the Royal Physiographic Society in Lund (C.F), Foundation of Tage Blucher for Medical Research (K.S.), Dr P. Håkansson (K.B), Fredrik and Ingrid Thuring (K.B), Lars Hierta (K.B. K.S), Âke Wiberg (K.B), Åhlén (K.B.), Tore Nilsson and Magnus Bergvall (K.B).

\section{Author details}

'Department of Experimental Medical Science, Lund University, Lund, Sweden. ${ }^{2}$ Department of Applied Nutrition and Food Chemistry, Section of Food Hygiene, Lund University, Lund, Sweden. ${ }^{3}$ Present address: Department of Health Sciences, Swedish Winter Sports Research Centre, Mid Sweden University, Östersund, Sweden.

Received: 28 June 2012 Accepted: 21 November 2012 Published: 26 November 2012

\section{References}

1. Shaw JE, Sicree RA, Zimmet PZ: Global estimates of the prevalence of diabetes for 2010 and 2030. Diabetes Res Clin Pract 2010, 87:4-14.

2. Smith BW, Adams LA: Nonalcoholic fatty liver disease and diabetes mellitus, pathogenesis and treatment. Nat Rev Endocrinol 2011, 7:456-465.

3. Backhed F, Ding H, Wang T, Hooper LV, Koh GY, Nagy A, Semenkovich CF, Gordon J: The gut microbiota as an environmental factor that regulates fat storage. Proc Natl Acad Sci USA 2004, 101:15718-15723.

4. Larsen N, Vogensen FK, van den Berg FW, Nielsen DS, Andreasen AS, Pedersen BK, Al-Soud WA, Sorensen SJ, Hansen LH, Jakobsen M: Gut microbiota in human adults with type 2 diabetes differs from nondiabetic adults. PloS One 2010, 5:e9085.

5. Turnbaugh PJ, Backhed F, Fulton L, Gordon J: Diet-induced obesity is linked to marked but reversible alterations in the mouse distal gut microbiome. Cell Host Microbe 2008, 3:213-223.

6. Cani PD, Delzenne NM: Gut microflora as a target for energy and metabolic homeostasis. Curr Opin Clin Nutr Metab Care 2007, 10:729-734.

7. Cani PD, Neyrinck AM, Fava F, Knauf C, Burcelin RG, Tuohy KM, Gibson GR, Delzenne NM: Selective increases of bifidobacteria in gut microflora improve high-fat-diet-induced diabetes in mice through a mechanism associated with endotoxaemia. Diabetologia 2007, 50:2374-2383.

8. Membrez M, Blancher F, Jaquet M, Bibiloni R, Cani PD, Burcelin RG, Corthesy I, Mace K, Chou CJ: Gut microbiota modulation with norfloxacin and ampicillin enhances glucose tolerance in mice. FASEB J 2008, 22:24162426.

9. Cani PD, Bibiloni R, Knauf C, Waget A, Neyrinck AM, Delzenne NM, Burcelin $R$ : Changes in gut microbiota control metabolic endotoxemia-induced inflammation in high-fat diet-induced obesity and diabetes in mice. Diabetes 2008, 57:1470-1481.

10. Esposito E, lacono A, Bianco G, Autore G, Cuzzocrea S, Vajro P, Canani RB, Calignano A, Raso GM, Meli R: Probiotics reduce the inflammatory response induced by a high-fat diet in the liver of young rats. J Nutr 2009, 139:905-911.

11. Ma X, Hua J, Li Z: Probiotics improve high fat diet-induced hepatic steatosis and insulin resistance by increasing hepatic NKT cells. J Hepatol 2008, 49:821-830.

12. Rubino F, R'Bibo SL, del Genio F, Mazumdar M, McGraw TE: Metabolic surgery, the role of the gastrointestinal tract in diabetes mellitus. Nat Rev Endocrinol 2010, 6:102-109.

13. Cabrera C, Artacho R, Gimenez R: Beneficial effects of green tea-a review. J Am Coll Nutr 2006, 25:79-99.

14. Klaus S, Pultz S, Thone-Reineke C, Wolfram S: Epigallocatechin gallate attenuates diet-induced obesity in mice by decreasing energy absorption and increasing fat oxidation. Int J Obes (Lond) 2005, 29:615-623.

15. Bose M, Lambert JD, Ju J, Reuhl KR, Shapses SA, Yang CS: The major green tea polyphenol, (-)-epigallocatechin-3-gallate, inhibits obesity, metabolic syndrome, and fatty liver disease in high-fat-fed mice. J Nutr 2008, 138:1677-1683.

16. Ikeda I, Hamamoto R, Uzu K, Imaizumi K, Nagao K, Yanagita T, Suzuki Y, Kobayashi M, Kakuda T: Dietary gallate esters of tea catechins reduce deposition of visceral fat, hepatic triacylglycerol, and activities of hepatic enzymes related to fatty acid synthesis in rats. Biosci Biotechnol Biochem 2005, 69:1049-1053.

17. Murase T, Nagasawa A, Suzuki J, Hase T, Tokimitsu I: Beneficial effects of tea catechins on diet-induced obesity, stimulation of lipid catabolism in the liver. Int J Obes Relat Metab Disord 2002, 26:1459-1464.

18. Wolfram S, Raederstorff D, Wang Y, Teixeira SR, Elste V, Weber P: TEAVIGO (epigallocatechin gallate) supplementation prevents obesity in rodents by reducing adipose tissue mass. Ann Nutr Metab 2005, 49:54-63. 
19. Wolfram S, Wang Y, Thielecke F: Anti-obesity effects of green tea, from bedside to bench. Mol Nutr Food Res 2006, 50:176-187.

20. Nagao T, Hase T, Tokimitsu I: A green tea extract high in catechins reduces body fat and cardiovascular risks in humans. Obesity (Silver Spring) 2007, 15:1473-1483.

21. Dulloo AG, Duret C, Rohrer D, Girardier L, Mensi N, Fathi M, Chantre P, Vandermander J: Efficacy of a green tea extract rich in catechin polyphenols and caffeine in increasing 24-h energy expenditure and fat oxidation in humans. Am J Clin Nutr 1999, 70:1040-1045.

22. Nagao T, Meguro S, Hase T, Otsuka K, Komikado M, Tokimitsu I, Yamamoto $T$, Yamamoto K: A catechin-rich beverage improves obesity and blood glucose control in patients with type 2 diabetes. Obesity (Silver Spring) 2009, 17:310-317

23. Koo SI, Noh SK: Green tea as inhibitor of the intestinal absorption of lipids, potential mechanism for its lipid-lowering effect. J Nutr Biochem 2007, 18:179-183.

24. Barthelmebs L, Divies C, Cavin JF: Knockout of the p-coumarate decarboxylase gene from Lactobacillus plantarum reveals the existence of two other inducible enzymatic activities involved in phenolic acid metabolism. Appl Environ Microbiol 2000, 66:3368-3375.

25. Osawa R, Kuroiso K, Goto S, Shimizu A: Isolation of tannin-degrading lactobacilli from humans and fermented foods. Appl Environ Microbiol 2000, 66:3093-3097.

26. Vaquero I, Marcobal A, Munoz R: Tannase activity by lactic acid bacteria isolated from grape must and wine. Int J Food Microbiol 2004, 96:199-204.

27. Aziz NH, Farag SE, Mousa LA, Abo-Zaid MA: Comparative antibacterial and antifungal effects of some phenolic compounds. Microbios 1998, 93:43-54.

28. Lee JH, Shim JS, Lee JS, Kim JK, Yang IS, Chung MS, Kim KH: Inhibition of pathogenic bacterial adhesion by acidic polysaccharide from green tea (Camellia sinensis). J Agric Food Chem 2006, 54:8717-8723.

29. Ankolekar C, Johnson D, Pinto MD, Johnson K, Labbe R, Shetty K: Inhibitory potential of Tea polyphenolics and influence of extraction time against helicobacter pylori and lack of inhibition of beneficial lactic acid bacteria. J Med Food 2011, 14:1321-1329.

30. Ahn Y-J, Sakanaka S, Kim M-J, Kawamura T, Fujisawa T, Mitsuoka T: Effect of green tea extract on growth of intestinal bacteria. Microbial Ecol Health Dis 1990, 3:335-338.

31. Karlsson CL, Molin G, Fak F, Johansson Hagslatt ML, Jakesevic M, Hakansson A, Jeppsson B, Westrom B, Ahrne S: Effects on weight gain and gut microbiota in rats given bacterial supplements and a high-energy-dense diet from fetal life through to 6 months of age. Br J Nutr 2011, 106:887-895.

32. Gustafsson RJ, Ohlsson B, Benoni C, Jeppsson B, Olsson C: Mucosaassociated bacteria in two middle-aged women diagnosed with collagenous colitis. World J Gastroenterol 2012, 18:1628-1634

33. Falk A, Olsson C, Ahrne S, Molin G, Adawi D, Jeppsson B: Ileal pelvic pouch microbiota from two former ulcerative colitis patients, analysed by DNAbased methods, were unstable over time and showed the presence of Clostridium perfringens. Scand J Gastroenterol 2007, 42:973-985.

34. Zheng D, Alm EW, Stahl DA, Raskin L: Characterization of universal smallsubunit rRNA hybridization probes for quantitative molecular microbial ecology studies. Appl Environ Microbiol 1996, 62:4504-4513.

35. Hall TA: BioEdit, a user-friendly biological sequence alignment editor and analysis program for windows 95/98/NT. Nucleic Acids Symp 1999, 41:95-98.

36. Cole JR, Wang Q, Cardenas E, Fish J, Chai B, Farris RJ, Kulam-Syed-Mohideen AS, McGarrell DM, Marsh T, Garrity GM, Tiedje JM: The ribosomal database project, improved alignments and new tools for rRNA analysis. Nucleic Acids Res 2009, 37:D141-D145.

37. Krebs CJ: Ecological methodology. 2nd edition. California: Benjamin Cummings; 1998.

38. Magurran AE: Ecological diversity and its measurements. London: Champman and Hall; 1996

39. Vandesompele J, De Preter K, Pattyn F, Poppe B, Van Roy N, De Paepe A Speleman F: Accurate normalization of real-time quantitative RT-PCR data by geometric averaging of multiple internal control genes. Genome Biol 2002, 3:RESEARCH0034.

40. Matthews DR, Hosker JP, Rudenski AS, Naylor BA, Treacher DF, Turner RC Homeostasis model assessment, insulin resistance and beta-cell function from fasting plasma glucose and insulin concentrations in man. Diabetologia 1985, 28:412-419.
41. Best DJ RD: Algorithm AS 89, the upper tail probabilities of spearmans rho. Applied Statistics 1975, 24:377-379.

42. Myles Hollander MWD: Nonparametric statistical methods. New York: John Wiley \& Sons; 1973

43. Hothorn THK, Van de Wiel MA, Zeileis A: A lego system for conditional interference. Am Stat 2006, 24:257-263.

44. Hothorn THK, Van de Wiel MA, Zeileis A: Implementing a class of permutation tests, The coin package. J Stat Softw 2008, 28:1-23.

45. Friedman M, Levin CE, Choi SH, Kozukue E, Kozukue N: HPLC analysis of catechins, theaflavins, and alkaloids in commercial teas and green tea dietary supplements, Comparison of water and $80 \%$ ethanol/water extracts. J Food Sci 2006, 71:C328-C337.

46. Juhel C, Armand M, Pafumi Y, Rosier C, Vandermander J, Lairon D: Green tea extract (AR25) inhibits lipolysis of triglycerides in gastric and duodenal medium in vitro. J Nutr Biochem 2000, 11:45-51.

47. Kobayashi Y, Suzuki M, Satsu H, Arai S, Hara Y, Suzuki K, Miyamoto Y, Shimizu M: Green tea polyphenols inhibit the sodium-dependent glucose transporter of intestinal epithelial cells by a competitive mechanism. J Agric Food Chem 2000, 48:5618-5623.

48. Naz S, Siddiqi R, Dew TP, Williamson G: Epigallocatechin-3-gallate inhibits lactase but is alleviated by salivary proline-rich proteins. J Agric Food Chem 2011, 59:2734-2738.

49. Everard A, Lazarevic V, Derrien M, Girard M, Muccioli GG, Neyrinck AM, Possemiers S, Van Holle A, Francois P, de Vos WM, et al: Responses of gut microbiota and glucose and lipid metabolism to prebiotics in genetic obese and dietinduced leptin-resistant mice. Diabetes 2011, 60:2775-2786.

50. Santacruz A, Collado MC, Garcia-Valdes L, Segura MT, Martin-Lagos JA, Anjos T, Marti-Romero M, Lopez RM, Florido J, Campoy C, Sanz Y: Gut microbiota composition is associated with body weight, weight gain and biochemical parameters in pregnant women. Br J Nutr 2010 104:83-92.

51. Zhang H, DiBaise JK, Zuccolo A, Kudrna D, Braidotti M, Yu Y, Parameswaran $P$, Crowell MD, Wing R, Rittmann BE, Krajmalnik-Brown R: Human gut microbiota in obesity and after gastric bypass. Proc Natl Acad Sci USA 2009, 106:2365-2370.

52. Velayudham A, Dolganiuc A, Ellis M, Petrasek J, Kodys K, Mandrekar P, Szabo G: VSL\#3 probiotic treatment attenuates fibrosis without changes in steatohepatitis in a diet-induced nonalcoholic steatohepatitis model in mice. Hepatology 2009, 49:989-997.

53. Zhou J, Febbraio M, Wada T, Zhai Y, Kuruba R, He J, Lee JH, Khadem S, Ren $\mathrm{S}$, Li S, et al: Hepatic fatty acid transporter Cd36 is a common target of LXR, PXR, and PPARgamma in promoting steatosis. Gastroenterology 2008, 134:556-567.

54. Osman N, Adawi D, Ahrne S, Jeppsson B, Molin G: Probiotics and blueberry attenuate the severity of dextran sulfate sodium (DSS)-induced colitis. Dig Dis Sci 2008, 53:2464-2473.

55. Mulder TP, Rietveld AG, van Amelsvoort JM: Consumption of both black tea and green tea results in an increase in the excretion of hippuric acid into urine. Am J Clin Nutr 2005, 81:256S-260S.

56. Roowi S, Stalmach A, Mullen W, Lean ME, Edwards CA, Crozier A: Green tea flavan-3-ols, colonic degradation and urinary excretion of catabolites by humans. J Agric Food Chem 2010, 58:1296-1304.

57. Siegmund B, Rieder F, Albrich S, Wolf K, Bidlingmaier C, Firestein GS, Boyle $D$, Lehr HA, Loher F, Hartmann G, et al: Adenosine kinase inhibitor GP515 improves experimental colitis in mice. J Pharmacol Exp Ther 2001 296:99-105.

58. Osman N, Adawi D, Ahrne S, Jeppsson B, Molin G: Endotoxin- and D-galactosamine-induced liver injury improved by the administration of lactobacillus. Bifidobacterium and blueberry. Dig Liver Dis 2007 39:849-856.

59. Park HJ, Lee JY, Chung MY, Park YK, Bower AM, Koo SI, Giardina C, Bruno RS: Green tea extract suppresses NFkappaB activation and inflammatory responses in diet-induced obese rats with nonalcoholic steatohepatitis. J Nutr 2012, 142:57-63.

60. Derrien M, Van Baarlen P, Hooiveld G, Norin E, Muller M, de Vos WM: Modulation of mucosal immune response, tolerance, and proliferation in mice colonized by the mucin-degrader akkermansia muciniphila. Front Microbiol 2011, 2:166.

61. Raederstorff DG, Schlachter MF, Elste V, Weber P: Effect of EGCG on lipid absorption and plasma lipid levels in rats. J Nutr Biochem 2003, $14: 326-332$ 
62. Sobolova L, Skottova N, Vecera R, Urbanek K: Effect of silymarin and its polyphenolic fraction on cholesterol absorption in rats. Pharmacol Res 2006, 53:104-112.

63. Derrien M, van Passel MW, van de Bovenkamp JH, Schipper RG, de Vos WM, Dekker J: Mucin-bacterial interactions in the human oral cavity and digestive tract. Gut Microbes 2010, 1:254-268.

64. Swidsinski A, Dorffel Y, Loening-Baucke V, Theissig F, Ruckert JC, Ismail M, Rau WA, Gaschler D, Weizenegger M, Kuhn S, et al: Acute appendicitis is characterised by local invasion with Fusobacterium nucleatum/ necrophorum. Gut 2011, 60:34-40.

65. Png CW, Linden SK, Gilshenan KS, Zoetendal EG, McSweeney CS, Sly LI, McGuckin MA, Florin TH: Mucolytic bacteria with increased prevalence in IBD mucosa augment in vitro utilization of mucin by other bacteria. Am J Gastroenterol 2010, 105:2420-2428.

66. Turnbaugh PJ, Hamady M, Yatsunenko T, Cantarel BL, Duncan A, Ley RE, Sogin ML, Jones WJ, Roe BA, Affourtit JP, et al: A core gut microbiome in obese and lean twins. Nature 2009, 457:480-484.

67. Wang M, Karlsson C, Olsson C, Adlerberth I, Wold AE, Strachan DP, Martricardi PM, Aberg N, Perkin MR, Tripodi S, et al: Reduced diversity in the early fecal microbiota of infants with atopic eczema. J Allergy Clin Immunol 2008, 121:129-134.

68. Wang M, Ahrne S, Jeppsson B, Molin G: Comparison of bacterial diversity along the human intestinal tract by direct cloning and sequencing of 165 rRNA genes. FEMS Microbiol Ecol 2005, 54:219-231.

69. Pilloni G, Granitsiotis MS, Engel M, Lueders T: Testing the limits of 454 pyrotag sequencing, reproducibility, quantitative assessment and comparison to T-RFLP fingerprinting of aquifer microbes. PLoS One 2012, 7:e40467.

\section{doi:10.1186/1743-7075-9-105}

Cite this article as: Axling et al:: Green tea powder and Lactobacillus plantarum affect gut microbiota, lipid metabolism and inflammation in high-fat fed C57BL/6J mice. Nutrition \& Metabolism 2012 9:105.

\section{Submit your next manuscript to BioMed Central and take full advantage of:}

- Convenient online submission

- Thorough peer review

- No space constraints or color figure charges

- Immediate publication on acceptance

- Inclusion in PubMed, CAS, Scopus and Google Scholar

- Research which is freely available for redistribution 